\title{
POLYKETONES AND POLYSULFONES FOR CONSERVATION IN THE ETHYLENE POLYMER INDUSTRY
}

PROGRESS REPORT NO. 2

APRIL - SEPTEMBER 1978

December 1978

PROCESS SCIENCES DIVISION

DEPARTMENT OF ENERGY AND ENVIRONMENT

BROOKHAVEN NATIONAL LABORATORY ASSOCIATED UNIVERSITIES, INC.

UNDER CONTRACT NO. EY-76-C-02-0016 WITH THE

UNITED STATES DEPARTMENT OF ENERGY 


\section{DISCLAIMER}

This report was prepared as an account of work sponsored by an agency of the United States Government. Neither the United States Government nor any agency Thereof, nor any of their employees, makes any warranty, express or implied, or assumes any legal liability or responsibility for the accuracy, completeness, or usefulness of any information, apparatus, product, or process disclosed, or represents that its use would not infringe privately owned rights. Reference herein to any specific commercial product, process, or service by trade name, trademark, manufacturer, or otherwise does not necessarily constitute or imply its endorsement, recommendation, or favoring by the United States Government or any agency thereof. The views and opinions of authors expressed herein do not necessarily state or reflect those of the United States Government or any agency thereof. 


\section{DISCLAIMER}

Portions of this document may be illegible in electronic image products. Images are produced from the best available original document. 


\section{POLYKETONES AND POLYSULFONES FOR CONSERVATION IN THE ETHYLENE POLYMER INDUSTRY}

\section{PROGRESS REPORT NO. 2 \\ APRIL - SEPTEMBER 1978}

Contributors:

Meyer Steinberg

Richard Johnson

William Cordes*

Donald Goodman*

WORK PERFORMED FOR. THE

DIVISION OF INDUSTRIAL ENERGY CONSERVATION

UNITED STATES DEPARTMENT OF ENERGY

WASHINGTON, D.C. 20545

PROCESS SCIENCES DIVISION DEPARTMENT OF ENERGY AND ENVIRONMENT

\author{
M. Steinberg, Head \\ R. Johnson, Project Leader
}

This report was prepared as

This report was prepared as an account of work United $S$ by the United States Government. Neither the Energy States nor the United States Department of Energy, nor any of their employees, nor any of their confractors, subcontractors, or their employees, makes any warranty, express or implied, or assumes any legal liability or responsibility for the accuracy, completeness or usefulness of any information, apparatus, product or infringe privasely of represents that its use would no

BROOKHAVEN NATIONAL LABORATORY UPTON, NEW YORK 11973 

I. Introduction $\quad: \quad 1$

Figures . . iv

Tables. v v v v v v v v v

II. Description of Co-60 Gamma Radiation Experiments 2

IIT. Results of Co-60 Gamma Radiation Experiments with Ethylene and $\mathrm{CO}$. 4

IV. Results of Co-60 Gamma Radiation Experiments with Ethylene and $\mathrm{SO}_{2} \quad 6$

V. Description of Electron Beam Experiment 8

VI. Electron Energy Utilization and Bremstrahlung Radiation Efficiencies for the Experimental Reaction Vessels

VII. Results of Electron Beam Copolymerization of Ethylene and CO

VIII. Results of Electron Beam Copolymerization of Ethylene and $\mathrm{SO}_{2}$

IX. Experimental Results of Terpolymerization of Ethylene with $\mathrm{SO}_{2}$ and $\mathrm{CO}$

X. Copolymer 'Characterization and Property Measurements 18

XI. Conclusions · 19

Acknowledgement $\quad 20$

References $\quad 21$ 
1. BNL Co ${ }^{60}$ gamma irradiation facility.

2. Heavy walled 2-in. O.D. reaction vesse1.

3. Et-CO copolymer from runs 50 and 66 .

4. $c^{60}$ gamma copolymerization of ethylene and $c 0$. Overall G value vs. radiation intensity.

5. $\mathrm{Co}^{60}$ gamma copolymerization of ethylene and $\mathrm{CO}$. Overa11 G value vs. pressure.

6. $\mathrm{Co}^{60}$ gamma copolymerization of ethylene and $\mathrm{SO}_{2}$. Overall $\mathrm{G}$ value vs. radiation intensity.

7. $\mathrm{Co}^{60}$ gamma copolymerization of ethylene and $\mathrm{SO}_{2} \cdot$ Pressure vs. time - Run 70.

8. Et- $\mathrm{SO}_{2}$ copolymer from run 71 .

9. Assembled 3/4-in. 0.D. reaction vesse1 with pressure gauge, rupture disc, and valve.

10. Schematic of typical reaction vessel for electron beam copolymerization studies.

11. Reaction vesse1. in position for electron beam irradiation at E-Linac. 33

12. Co ${ }^{60}$ gamma and electron beam copolymerization of ethylene and $\mathrm{SO}_{2}$. Overall $G$ value vs. pressure.

13. Et- $\mathrm{SO}_{2}-\mathrm{CO}$ terpolymer from runs 67 and 73 .

14. Infrared spectra of ethylene copnlymers: (a) Et-CO, Run 54A;

(b) $\mathrm{Et}-\mathrm{SO}_{2}$, Run 70; and (c) $\mathrm{Et}-\mathrm{SO}_{2}-\mathrm{CO}$, Run $7: 2$.

15. Electron beam copolymerization of ethylene and co. Differential scanning calorimeter - Run 18.

16. Electron beam copolymerization of ethylene and $\mathrm{SO}_{2}$. Differential. scanning calorimeter - Run 29.

17. $\mathrm{Co}^{60}$ gamma terpolymerization of ethylene, $\mathrm{SO}_{2}$, and $\mathrm{CO}$. Differential scanning calorimeter - Run 67.

18. Electron beam copolymerization of ethylene and co. Thermogravimetric analysis - Run 18. 


\section{List of Figures (Cont.)}

Figure

Page

19. Electron beam copolymerization of ethylene and $\mathrm{SO}_{2}$. Thermogravimetric analysis - Run 29.

20. $\mathrm{Co}^{60}$ gamma terpolymerization of ethylene, $\mathrm{SO}_{2}$, and $\mathrm{Co}$. Thermogravimetric analysis - Run 67.

$\underline{\text { Table }}$

$$
\text { List of Tables }
$$

1. Co ${ }^{60}$ Gamma Radiation Copolymerization of Ethylene and Co Experimental Results

Page

2. $\mathrm{Co}^{60}$ Gamma Radiation Copolymerization of Ethylene and $\mathrm{SO}_{2}$ Experimental Results

3. Electron Energy Utilization Efficiencies for Reaction Vessels

4. Electron Beam Copolymerization of Ethylene and CO Experimental Results.

5. Electron Beam Copolymerization of Ethylene and $\mathrm{SO}_{2}$ Experimental. Results

6. Terpolymerization of Ethylene with $\mathrm{SO}_{2}$ and $\mathrm{C}$ Experimental Results

7. Ethylene- $\mathrm{SO}_{2}-\mathrm{CO}$ Terpolymer Analyses

8. Thermal Characteristics of the Copolymers Derived from DSC, TGA, and DTGA Analyses 


\section{POLYKETONES AND POLYSULFONES FOR CONSERVATION}

IN THE ETHYLENE POLYMER INDUSTRY

Progress Report No. 2

April-September

Summary

$\Lambda$ program is underway to investigate the substitution and introduction of $\mathrm{CO}$ and $\mathrm{SO}_{2}$ into high molecular weight polymers of ethylene for the purpose of conserving ethylene feedstock for the polymer market. Et-CO polyketone copolymers, $\mathrm{Et}_{-} \mathrm{SO}_{2}$ polysulfone copolymers and Et-CO-SO${ }_{2}^{-}$ terpolymers have been produced by Co-60 gamma radiation and by electron beam machine radiation. This is the first time that I-beam radiation has been used to produce these copolymers in high pressure systems. The yield for the 1:1 Et-CO polyketone copolymers appears to be square root dependent on the intensity. The electron machine radiation yields appear to be lower $\left(G=10^{2}\right.$ to $10^{3}$ ) than that obtained with co-60 gamma radiation $\left(G=10^{3}\right.$ to $\left.10^{4}\right)$ or with bremstrahlung radiation produced by the electron beam interacting with the pressure vessel. The lower yields may be due to the high radiation intensity' of the electron beam. The yield of $\mathrm{Et}-\mathrm{SO}_{2}$ polysulfone copolymer appears to be independent of radiation intensity and appears to be very high $\left(G=10^{4}\right.$ to $\left.10^{5}\right)$ either with Co-60 or electron machine radiation. A strong post-irradiation polymerization effect is observed in the Et-SO 2 copolymer system. This is the first time an Et-CO-SO 2 copolymer has been reported especlally with a content as low as 36 mole percent ethylene and 64 mole percent of combined $\mathrm{CO}$ and $\mathrm{SO}_{2}$. The Et copolymers ( 1 to 1 Et-CO and 1 to 1 Et-SO ${ }_{2}$ ) appear to be stable up to temperatures in the order of $275^{\circ}$ to $300^{\circ} \mathrm{C}$ and the Et-Co copolymer has shown good tensile strengths. Much further characterization and formulation of the copolymer and terpolymer systems are needed to determine their market value. 
POLYKETONES AND POLYSULFONES FOR -CONSERVATION

IN THE ETHYLENE POLYMER INDUSTRY

Progress Report No. 2

April-September 1978

\section{Introduction}

The principal objective of this investigation is to prepare ethylene polyketones and ethylcne polysulfones for determination of their usefulness in industry as a means of substituting low-cost and energy conservative materials in the ethylene polymer and copolymer market. ${ }^{(1,8)}$ In the case of the Et-CO polyketones, a joint program was set up between BNL and Tenneco Chemicals, Inc. (TCI) in which BNL would prepare the copolymers by radiation induced means and Tenneco would assist in characterization of the copolymers and also compare the results with thermochemical means of induction of copolymerization.

From an industrial application point of view, the use of electron machine radiation may be preferrable to Co-60 gamma radiation. We have thus set out to obtain copolymers with the use of electron beam radiation machines, something which has never been done before, in high pressure gas systems and to compare the results with the better understood gamma radiation experiments. In addition to the Co-60 gamma radiation facility, BNL has a Dynamitron electron accelerator facility producing electron radiation up to $3 \mathrm{MeV}$ energy for basic solid state physics research, which was used for the copolymerization experiments. Since the BNL electron machine was limited in energy, an electron linear accelerator (E-Linac) located at the University of Maryland (acquired from the Space Research Effects Laboratory (SREL)) was also used for the experiments 
described below which delivers electrons to a maximum energy of $10 \mathrm{eV}$. The following describes the results of the experimental work starting first with the Co-60 experiments and following with the electron machine radiation.

\section{Description of Co-60 Gamma Radiation Experiments}

Co-60 gamma-induced copolymerization experiments were continued $(1-3)$ for the purpose of establishing a basis for comparison with the electron beam experiments that were conducted concurrently. Smaller diameter vessels were initially required for performing the electron beam radiation experiments because of the need to limit the wall thickness to allow the electrons to penetrate the wall and deposit energy in the gas phase at a given pressure. The apparent low product yields that were obtained initially with the electron beam experiments in the small diameter reaction vessels led to an investigation of various methods of pretreating the vessel interior surfaces to reduce the possible inhibiting effect of the walls of the vessel. The other cause for lower radiation yields Is " due to impurities in the gaseous reactants.

I'the leaction vessels were generally made of Type-304 stainless steel tubing measuring $1 / 4-$ to $3 / 4-i n$. O.D. $x$ 13-in. 1ong, $1 \cup-1 / 2-i n$. of which extended directly in the radiation field. These vessels were connected ;...

to a pressure gauge mounted approximately fourteen feet through the water shielding above the top of the vessel to permit observation of the system pressure during submergence in the Co-60 gamma pool at BNL (see Fig. 1). The connecting 1/4-in. line contained a rupture disc assembly and a tee with a valve for filling and venting. Compressiontype fittings were used on the reactive tubes, and cone and threaded 
high-pressure fittings were used elsewhere. Several runs were also made in the high pressure, thick walled 2-in. O.D. $x$ 1-in. I.D. $x$ 11-in. .. long Inconel vessel (see Fig. 2) described in the previous report, (1) which also describes the support apparatus used for insertion of the reaction vessels into the gamma source. Since the vessel in all cases was in direct, contact with the gamma pool water maintained at $10^{\circ}$ to $13^{\circ} \mathrm{C}$, isothermal conditions were assumed for the polymerization. No internal reaction vessel temperatures were taken.

The polyketones were prepared by charging the evacuated apparatus with ethylene and CO premixed in gas cylinders. (C.P. grade supplied by Matheson Gas Products) and pressurized by means of a stainless steel diaphragm compressor. The fill connection was disconnected and the reaction apparatus was then transferred to the gamma pool for equilibrating with the pool water temperature prior to insertion into the Co-60 source holder annulus for irradiation. These runs were of the fallingpressure type, since there is a reduction in volume during polymerization and no attempt was made to replenish loss of reactants. The radiation energy. deposited inside the 2 -in. O.D. x 1-in. I.D. reaction vesse1 was measured by using a Fricke dosimeter, and calculated for the other vessels. After each run, excess gas was vented and the polymer, in the form of either a white powder or a solid white mass, was recovered and weighed for determination of yield.

The polysulfones were prepared in a similar manner except that a different filling procedure was required, since the $\mathrm{SO}_{2}$ component above certain concentrations (partial pressures) forms a liquid phase. The $\mathrm{SO}_{2}$ was transferred (from a C.P. grade Matheson gas products cylinder) 
batch-wise as a gas at low pressure and then condensed into the chilled reaction yessel. From the known pressure, volume, and temperature of the transfer system, the quantity of $\mathrm{SO}_{2}$ collected in the reaction system was calculated. The vessel containing this known quantity of $\mathrm{SO}_{2}$ was then charged with either pure ethylene gas or an ethylene-co mixture to the desired pressure by. means of the compressor. No attempt.was made to segregate product made in the liquid phese from product made in the gas phase by use of screens, as had been done in previous work. (3)

III. Results of Co-60 Gamma Radiation Experiments with Ethylene and CO The experimental results for the copolymerization of ethylene and Co by $\mathrm{Co}^{60}$ gamma radiation are given in Table 1 . All of these runs were made with Et-CO mixtures containing approximately $50 \% \mathrm{CO}$, since the highest polymerization rates had been obtained previously ${ }^{(2)}$ with mixtures at or near the azeotropic composition of $48.5 \%$ co-51.2\% ethylene.

The effect of vessel surface pretreatment was investigated to establish a procedure for obtaining optimum yields consistently. Runs 22 to 24 made at the same pressure (145 to $148 \mathrm{~atm}$ ), radiation intensity $(0.60 \mathrm{Mrad} / \mathrm{hr})$ and total dose $(1.80 \mathrm{Mrad})$ in the same size vessel $(1 / 2-$ in. O.D.) show a factor of 4 range in product yield and overall $G$ value. The lowest yield $(0.092 \mathrm{~g})$ and $\mathrm{G}$ value $(270$ molecules/100 eV) was obtained in run 24 with a vessel constructed of new tubing that had been flushed only with acetone. In run 22, a new vessel was cleaned with. a rag after flushing with acetone which led to an improved yield $(0.126 \mathrm{~g})$ and $\mathrm{a}$ higher $\mathrm{G}$ value $(370$ molecules $/ 100 \mathrm{eV})$. The best yield $(0.366 \mathrm{~g})$ and highest G value (1080 molecules/100 eV) were obtained in run 23 with a new vessel that had been Teflon spray coated subsequent to 
acetone flushing and rag cleaning. The inhibiting effect of the reaction vessel wall may be apparent in run 25 made with a 1/4-in. 0:D. vessel which has a two-fold increased surface-area-to-volume ratio (compared to the previous runs made with $1 / 2-i n .0 . D$. vessels) and resulted in no product formation at all, nothwithstanding the use of a Teflon coating. Vessels that were only mechanically cleaned with a rotary wire-brush tube cleaner (runs $44,49,50,52 \mathrm{~A}$ to $54 \mathrm{~B}$ ) as well as an oxide-coated vessel (run 51) were also tested and were found to produce inconsistent results. In general, good yields and $G$ values were obtained with vessels that had been usèd in previous runs which had been pretreated (Teflon coated, wire brushed, etc.), emptied of product by rodding and tapping, and reused in subsequent runs without any other pretreatment. Such vessels are designated as "used" in the Vessel Pretreatment column of Table 1, The copolymer product from these runs was recovered as a white powder or as pieces of broken rod that pulverized quite readily. Some typical Et-Co product is shown in Fig. 3 from runs 50 and 66.

Although the effect of impurities per se in the gas mixtures was not specifically investigated, a variation in yield and $G$ value was noted with the three different supply cylinders of Et-CO mixtures used in . these runs as designated by the co content. $(48.8,49.7$, and $49.9 \%)$. The 49.7 and $49.9 \%$ mixtures consistently gave lower yields and $G$ values. that cannot be attributed to their slightly higher $C 0$ content but rather may be the result of higher impurity or contaminant content. Analysis of the $49.9 \%$ mixture showed $0.2 \%$ air by volume, while none was detected in the $48.8 \%$ mixture. Oxygen is known to be an inhibitor in free radical initiated polymerizations and thus it appears that impurity content may be the cause of the inconsistent lower results. 
The effect of radiation intensity, I, on the overall $G$ value is shown in Fig. 4, based on runs 46 through 48, 50, 55A, 55B, 56A, and $56 \mathrm{~B}$ made with $48.8 \% \mathrm{CO}$ at 140 to 150 atm and $10^{\circ}$ to $13^{\circ} \mathrm{C}$ and between dose rates of 0.044 to $0.90 \mathrm{Mrads} / \mathrm{hr}$. The data indicate a -0.38 power dependence of the overall $G$ value on the intensity, $I$, or a 0.62 power dependence of the overall rate of polymerization, Q, on the intensity. This is in good agreement with the previous work at BNI., (2) which indicated a 0.60 power dependence of rate on intensity. The closeness to a square root dependence indicates a free radical mechanism for initiation and termination of the polymerization reaction.

The effect of pressure on overall.G value is shown in Fig. 5, based on runs $7,9,10,15,16$ (previous report ${ }^{(1)}$ ), and 23 , all made with $48.8 \% \mathrm{CO}$ at $10^{\circ}$ to $13^{\circ} \mathrm{C}$ and at 0.60 and $0.71 \mathrm{Mrad} / \mathrm{hr}$ intensity. Since pressures were not maintalned conetant, average pressures were used for the correlation. The limited data indicate a 0.81 power dependence of the overall $G$ value on the pressure, which is again in close agreenent with the previous value ${ }^{(2)}$ of 0.83 for a $50 \%$ co mixture.

1V. Resulte of Co-60 Gamma Radiation Experiments with Ethylene and $\mathrm{SO}_{2}$

The experimental results for the copolymerization of ethyleme and $\mathrm{SO}_{2}$ by gamma induced radiation are given in Table 2. The overall $\mathrm{G}$ value ranged from $1.36 \times 10^{3}$ molecules $/ 100 \mathrm{eV}$ for run 26 at 98 to 75 atm to $6.9 \times 10^{4}$ molecules/100 eV for run 69 at 571-204 atm. Decreasing the radiation intensity to $0.030 \mathrm{Mrad} / \mathrm{hr}$ from $0.60 \mathrm{Mrad} / \mathrm{hr}$ resulted in an increase in overail G value to $9.3 \times 10^{4}$ molecules/100 eV in run 71 . A plot of overall G value vs: radiation intensity, I, is shown in Fig. 6 and indicates a -0.12 power dependence of the $G$ value on the intensity, 
or a 0.88 power dependence of the overall polymerization rate, $Q$, on the intensity. The data points represent runs 11,13 (from previous report ${ }^{(1)}$, and 69,70 , and 71 . The much lower dependence of yield on intensity indicates that the chains of polymers are not terminated biradically. It is also possible that an ionic mechanism of initiation may also be operative. In any case the copolymerization of ethylene and $\mathrm{SO}_{2}$ : proceeds at a much greater rate than the ethylene-CO copolymerization.

Large overall pressure drops were observed in all of these runs because of the high polymerization rates of ethylene and $\mathrm{SO}_{2}$ and also because of the large deviation of ethylene from ideality. The compressibility of $100 \%$ ethylene varies approximately as the 0.8 power of the pressure in this range. The gas phase in the Et- $\mathrm{SO}_{2}$ system consists mainly of ethylene, since the $\mathrm{SO}_{2}$ vapor pressure at $20^{\circ} \mathrm{C}$ is only 3.3 atm. In run 26, a steady drop in pressure from 98 to 75 atm was observed during the 30 min irradiation period. In runs 69 and 70 conducted at higher pressure, a post-irradiation effect was observed. The data in Table 2 indicates final pressures following this post-irradiation effect. In run 69, the system pressure dropped from the initial 571 atm to 463 atm at the termination of irradiation. The vessel was then taken out of the source but left underwater in the gamma pool to maintain constant temperature. In the subsequent 5 min period, the pressures dropped to $272 \mathrm{~atm}$, and leveled off at $204 \mathrm{~atm}$ after an additional $10 \mathrm{~min}$. In run 70, a similar post-irradiation effect was observed. For this run, the reaction vessel was inserted and removed from the Co-60 source three times to test the effect of intermittent radiation dose. A plot of the system 
pressure vs. time is shown in Fig. 7. Despite the volume reduction which results from the polymerization reaction, a pressure increase was observed during the initial part of the irradiation periods in this run. This also occurred in the previous $\mathrm{Et}-\mathrm{SO}_{2}$ runs. The increase in pressure is most likely due to a rise in temperature caused by a large exotherm resulting from the high rate of polymerization. Polymer formation also tends to impede heat transfer through the vessel wall so that at high rates of polymerization isothermal conditions are difficult to maintail. The product from these runs was typically a fine white powder (see Fig. 8).

This strong post-irradiation effect in the $\mathrm{Et}-\mathrm{SO}_{2}$ polymerization system appears to be quite unique and indicates a relatively long-1ived species (free radical or ionic) which can propagate the chain reaction almost: to completion. From a manufacturing point of view, this can make the system economically very attractive.

\section{Description of Electron Beam Experiment}

The electron beam experiments were conducted with the Dynamitron lucated at BNL and also conducted with the SREL E-Linac electron linear accelerator located at the University of Maryland.

The Dynamitron, manufactured.:by Radiation Dynamics, Inc. is a DC accelerator which generates a beam of continuous intensity. The model in use at $\mathrm{BNL}$ has a design rating of $3 \mathrm{MeV}$ and is provided with a magnetic scanning device (scan-horn) that can spread the beam up to two feet in width.

The SREL E-Linac is of the microwave linear accelerator-type which generates a pulsed beam at energies up to $10 \mathrm{MeV}$. All of the 
runs in this accelerator were made with a beam pulse length of 6 usec and at 60 pulse repetitions per second. A magnetic beam spreader and placement of the reaction tubes three feet away from the beam port resulted in spread of the beam over the 13-in. long tubes, with a dose distribution ranging from zero at the ends of the tube to a maximum at the center.

Dose measurements were made with radiochromic plastic film as described by McLaughlin et al. (4) Preliminary dose calculations were made by using the method described by cleland and Farrel1. (5)

The reaction vessels were made on Type-30.4 stainless tubing up to 3/4-in. O.D., and were usually 13-in. 1ong. They were mounted horizontally and provided with a valve, rupture disc assembly, and pressure gauge which could be observed remotely with a TV camera. Cooling was provided by means of one (or two in the case of the 3/4-in. O.D. reaction tubes) 1/4-in. O.D. stainless steel tubes either brazed or cemented to the rear of the reaction tubes along the full length. Cyanoacrylate cement with metal powder provided sufficient heat transfer to maintain the vessels very close to the cooling water temperature $10^{\circ}$ to $20^{\circ} \mathrm{C}$ ). High pressure cone and threaded fittings were used on the interconnecting lines. The thin walled ( 0.035 to 0.049 in.) reaction tubes were initially welded to the lines, but were subsequently connected with compression fittings, for ease of reassembly. An assembled 3/4-in. 0.D. reaction vessel is shown in Fig. 9 and a schematic diagram is shown in Fig. 10. Fig. 11 shows a reaction vessel in position for electron beam irradiation at the E-Linac. 
VI. Electron Energy Utilization and Bremstrahlung Radiation Efficiencies for the Experimental Reaction Vessels

The electron utilization efficiencies for the various size reaction vessels used experimentally were calculated for a preliminary determination of dose and compared with subscquent measured values ${ }^{(4)}$ obtained by radiochromic film dosimetry and are shown in Table 3 . The method described by Cleland and Farrell ${ }^{(5)}$ was used in the calculations, which is based on the energy dissipation table of Spencer ${ }^{(6)}$ and electron range data of Berger and Seltzer. (7) An additional efficiency loss of $62 \%$ was estimated by graphical step-wise integration for the $1 / 2-$ and 3/4-in. O.D. tubes due to the apparent Increase in wall thickness resulting from the curvature of the tubes. The total energy collected by the vessel was determined by the current collected by the reaction vessel and the electron energy impinging on the vessel. The calculated utilization efficiency values were generally higher than the measured values except at the tailend of the energy distribution curve, where the calculated values were too low due to omission of $x$-ray conversion in the computation by Spencer. The measured values were used in all of the overall $\mathrm{G}$ value tabulations.

For comparison, calculations of utilization efficiencies were made for larger size vessels using a higher strength, lower $\mathrm{Z}$ and lower density material such as titanium. The maximum allowable pressure was limited to the allowable stresșes in the vessel walls which is based on a standard safety factor of 5 . Special vessel design could allow larger allowable stresses. Energy. loss in the walls of larger tubes due to curvature.can be minimized by use of a narrow beam scanning 
only along the tube axis, or by use of staggered tubes. Utilization efficiencies of 37 and $46 \%$ were calculated on this basis for 1 and:2in. O.D. titanium tubes, respectively. Realistically, a $25 \%$ efficiency should be possible in a commercial system, allowing for higher pressure operation, wall curvature effects, and inherent inaccuracy in the method of calculation. It can also be pointed out that operating at the lower pressure of 100 atm where the compressibility of the Et-CO gas is close to a minimum may provide an optimum use of gas density. Yield and copolymer characterization data are needed to confirm these points.

In addition tu direct electron energy deposition in the gaseous reactants bremstrahlung or $x$-rays are deposited due to the interaction of the high energy electrons with the vessel walls. The following is a description and estimate of this radiation source.

Energy for ionization, which produces free radicals in the monomer mixture, is imparted by the electrons in the electron beam during stepwise ionizing collisions with atomic electrons. The energetic free electrons also lose energy during passage through the electric field of a nucleus, which results in bremstrahlung or $x$-rays. Those $x$-rays appear as a continuous spectrum and, as with gamma rays, undergo a reduction in intensity by photoelectric absorption, Compton scattering, and electron-positron pair formation, all of which also contribute to free radical formation. The electron energy loss per unit length by radiation or $x-r a y(d E / d x)_{r a d}$ as compared to the energy loss by ionizing collision per unit length $(\mathrm{dE} / \mathrm{dx})_{\text {ioniz }}$ is given by

$$
\frac{(\mathrm{dE} / \mathrm{dx})_{\mathrm{rad}}}{(\mathrm{dE} / \mathrm{dx})_{\text {ioniz }}}=\frac{\mathrm{EZ}}{800} \text {, }
$$


where $\mathrm{E}$ is the electron energy in $\mathrm{MeV}$ and $\mathrm{Z}$ is the atomic number of the absorber.

Some of the electron energy is thus converted into radiation (x-rays) during passage through the vessel wall. This conversion was estimated for a thin walled vessel by the above equation (letting $\mathrm{dE}=\Delta \mathrm{E}$ and $\mathrm{dx}=\Delta \mathrm{x})$. The energy distribution after attenuation of the primary electron beam in a vertical 0.035 in. thick steel wall, assuming $2 \pi$ $\left(180^{\circ}\right)$ forward scattering of $x$-ray and also $2 \pi$ backscattering of $x$-ray from a rear parallel wall of the same thickness is thus:

\begin{tabular}{rrr} 
E, MeV & $\%$ x-rays: & $\%$ Electrons \\
\cline { 3 - 3 } 2 & 11 & 89 \\
4 & 5 & 95 \\
10 & 3 & 97
\end{tabular}

Attenuation of the $x$-rays in the steel wall ${ }^{(5)}$ was neglected but would probably be offset by additional scattering of $x$-rays from the upper and lower portion of the vessel wall for a tube-shaped vessel. These values indicate that for thin walled steel tubing (0.035-in.) with electron energy $>2 \mathrm{MeV}$ only a small fraction of the energy is converted into $x$-rayo. Iarger $x$-ray fraction may be obtained with thicker wa1led vessels.

VII. Results of Electron Beam Copolymerization of Ethylene and CO The experimental results for the electron beam copolymerization of ethylene and $\mathrm{CO}$ are given in Táble 5. Several runs, especially during the initial phase, produced significant yields due to surface poisoning or gas contamination and were, therefore, not included in this table. A11 of the runs which are reported here were made with previously used 
or Tefion coated tubes to minimize the surface effect.

The best yield $(6.0 \mathrm{~g})$ and highest overall $\mathrm{G}$ value (7000 molecules/ $100 \mathrm{eV}$ ) was obtained in run 18 made at 483 to 350 atm with the large 2-in. O.D. x 1-in. I.D. Inconel vessel previously described. This overall $G$ value exceeds the maximum value obtained previously $\left(3970^{\circ}\right.$ molecules/100 eV, run 9, reference 1) under similar conditions but with Co-60 gamma radiation. Because of the thick vessel wall (1/2-in.) which exceeds the electron range (approx. 1/4-in.) at $7 \mathrm{MeV}$ in Inconel, the energy was essentially all bremsstrahlung ( $x$-rays). Since most of the electron energy was dissipated in the thick vessel wall, the energy utilization efficiency, $F_{e}$ ' (fraction of energy deposited in the reactant gas) was only $0.24 \%$ of the total energy deposited by the beam in the reaction vesse1. The vessel was not cooled effectively and it is. estimated that the temperature rose to approximately $50^{\circ} \mathrm{C}$ by the end of the run. This temperature rise could also have affected the polymerization rate and the product characteristics. The co content of the copolymer was measured to be $48.4 \mathrm{~mol} \%$, which indicates that approximately a $1: 1$ ratio of CO/Et copolymer was produced.

All of the other electron beam runs were made in the smaller thinwalled tubing at lower pressures (1.16 to $224 \mathrm{~atm}$ ) and resulted in overall. G values ranging from 23 to 165 molecules/100 eV or an average of 60 molecules/100 eV. These values are approximately an order of magnitude lower than the values obtained in the Co-60 gamma runs at comparable pressures in the 0.60 to $0.90 \mathrm{Mrad} / \mathrm{hr}$ intensity range. The energy utilization efficienty based on dosimetry measurements was $4.9 \%$ at $2 \mathrm{MeV}$ and $6.4 \%$ at 5 to $10 \mathrm{MeV}$ for the $1 / 2$-in. $\mathrm{x} .0 .035$-in. wa11 tubing. 
For the 1/2-in. 0.D. $x$ 0.065-in. wall and 3/4-in. 0.D. x 0.049-in. wall, estimated values of 2.9 and $7.5 \%$ were used based on dosimetry (see Table 3).

The product analysis of three of the runs indicated a CO/Et value close to 1 (Co molar concentrations of $47.1,45.8$, and $47.8 \%$ for runs $28,38$, and 39$) \cdot$

The electron beam runs give an indlcation that the utilization of the energy of the electron was low (as measured by the G values) in the runs made in the Llin walled tubing, where there was penetration of electrons. (See Sect. VI .. for energy distribution as electrons and bremsstrahlung.) This. is in contrast with run 18 (1/2-in. vessel wa11) where the $G$ value was higher than obtained previously by Co-60, radiation for similar conditions. The radiation consisted almost entirely of bremsstrahlung in run 18. The; conversion of electron energy into bremsstrahlung results in a lower energy utilization efficiency of the electron beam compared with efficiencies of up to 40 to. $50 \%$ that can be achieved with optimum design of thin-walled vessels made of less dense materials such as titanium and aluminum that permit penetration of electrons through the wall and deposition of electron: energy direcl. $y$ in the gaseous reactants The $0.24 \%$ efficiency achieved in run 18. is far from optimum for total conversion of electron energy into bremstrahlung, since the vessel was excessively thick.. The effect of pressure has to be further investi-. gated..., :

It should be pointed out that to our knowledge this is the first reported copolymerization of Et and CO by means of direct electron beam radiation. 
The effect of dose rate for the E-Linac as tabulated is not clear, since these values are mean dose rates rather than effective, instantaneous dose rates due to the pulse type of irradiation. The short irradiation pulses of $6 \mu \mathrm{sec}$ every $1.67 \times 10^{4} \mathrm{\mu sec}$ produced effective microvolume intensities $2.78 \times 10^{3}$ greater than the mean. While the beam produced by the Dynamitron is continuous, it is a scanning type of irradiation. which also gives a nonuniform, instantaneously high dose rate similar. to the E-Linac. The dose rate effect which has been elucidated in the Co-60 gamma work could be a basis for explaining the lower yie1ds, rates and $G$ values obtained in the runs with thin-walled tubing where the electrons penetrated the walls. The high yield, rate and $G$ value obtained in run 18 with the heavy walled vessel may be explained due to the more uniform deposition of bremsstrahlung energy similar to Co-60 gamma radiation energy but of a lower energy value.

VIII. Results of Electron Beam Copolymerization of Ethylene and $\mathrm{SO}_{2}$ The experimental results for the electron beam copolymerization of ethylene and $\mathrm{SO}_{2}$ are given in Table 5. Runs 29, 34, and 35. were made in a $1 / 2-i n$. O.D. vessel, each containing $11.2 \mathrm{~g} \mathrm{sO}_{2}$ (in both liquid and gas phases) and approximately $16.3 \mathrm{~g}$ ethylene. Overall $\mathrm{G}$ values ranged from 1330 to 3990 molecules/100 eV and are plotted in Fig. 12 together with the Co-60 gamma experimental data (runs 11, 13, 26, 69 . through 71 ). If the effect of radiation intensity on $G$ value is assumed to be negligible and the effect of electron energy and Co-60 gamma energy to be identical, the plot indicates a 2.1 power dependence of the $G$ value on the average system pressure. Analysis of product from runs 29,34 , and 35 indicated a 1:1 molar ratio of $\mathrm{SO}_{2}$ to ethylene. Even 
with the strong pressure effect on the yield, the Et-SO ${ }_{2}$ copolymer is readily made, since with almost any radiation-type initiator the yields and rates are relatively high.

IX. Experimental Results of Terpolymerization of Ethylene with $\mathrm{SO}_{2}$ and CO The terpolymerization of ethylene with $\mathrm{SO}_{2}$ and $\mathrm{Co}$ was briefly investigated. The experimental conditions and results are given in Table 6 . Runs 32, 33, 37, and 67 were made in 1/2-in. 0.D. reaction vessels containing $\mathrm{SO}_{2}$ in both the liquid and gas phases. After charging with $\mathrm{SO}_{2}$ the vessels were pressurized to 170 atm with an Et-CO mixture contalniug $48.8 \% \mathrm{CO}$. Reduction in pressure to approximately 150 atm resulted initially because of solubility of the Et-CO gas mixture in liquid $\mathrm{SO}_{2}$ and also because of the lower temperature $\left(10^{\circ}\right.$ to $\left.13^{\circ} \mathrm{C}\right)$ during irradiation. The highest yield of $6.4 \mathrm{~g}$ was obtained in run 64 , in which the maximum quantity of $\mathrm{SO}_{2}$ was used $(9.0 \mathrm{~g})$. This corresponds to an overall $\mathrm{G}$ value of $2.6 \times 10^{4}$ molecules/100 eV, assuming. an average polymer unit molecular weight of 43.2 based on earlier $\mathrm{Et}^{-\mathrm{SO}_{2}}$ analyses which indicated a slightly less than $1 / 1 \mathrm{SO}_{2} / \mathrm{Et}$ molar ratio. The lowest yield $(0.126 \mathrm{~g})$ and $\mathrm{G}$ value $\left(1.2 \times 10^{2}\right.$ molecules $\left./ 100 \mathrm{cV}\right)$ occurred in run 37 , which was the only electron beam run in this series. This effect may possibly be due to the electron intensity factor discussed in the Et-CO experiments. However, more experimental evidence is needed before a firm conclusion can be made.

Runs 72 thorugh 74 were made with $\mathrm{SO}_{2}$ in the vapor phase only and pressurized with the same Et-CO mixture to $680 \mathrm{~atm}$ in the 1arger 2 in. 0.D. Inconel reaction vessel. In each of the three runs a rapid pressure increase of 20 to 60 atm occurred within 4 to 5 min., which was apparently 
caused by a large exotherm. In addition, a post-irradiation effect was observed in run 74 , possibly because of the short irradiation period. The pressure in this run rose from 599 atm initially to a peak of 660 atm after a 5 min. irradiation period. After an additional 8 min., the pressure leveled off at $575 \mathrm{~atm}$. The tabulated pressures indicate the initial and final values only. The maximum yield of $3.18 \mathrm{~g}$ of product and $G$ value of $3.0 \times 10^{4}$ molecules/100 eV in run 74 compared with runs 72 and 73 indicated that the yield is decreased by increasing irradiation periods longer than 5 min.

The analyses of product from some of the runs are given in Table 7 . The $\mathrm{SO}_{2} /$ Et molar ratio is close to $1: 1$ in runs 32,33 , and 67 , and approximately $1: 2$ in run 37. The Co concentration is the lowest of the three components with a range between 0.9 and 22.2 mole \%. Run 67 is of interest from a conservation viewpoint because of its low ethylene concentration (36.1 and 38.7 mole \%). Further work is required for confirmation of these values. A portion of the hard, solid product mass that was removed from the bottom of the vessel $\left(\mathrm{SO}_{2}\right.$ liquid phase) from run 67 is shown in Fig. 13 together with the more powdery-like material from run 73.

The infrared spectrum for $\mathrm{Et}-\mathrm{SO}_{2}-\mathrm{SO}$ product from run 72 is shown in Fig. 14, together with the Et-CO spectrum from run $54 \mathrm{~A}$ and the $\mathrm{Et}-\mathrm{SO}_{2}$ spectrum from run 70 for comparison. The Et-SO${ }_{2}-\mathrm{CO}$ and $\mathrm{Et}_{-} \mathrm{SO}_{2}$ spectra are quite similar except for the carbony1 absorption brand at $\sim 1700 \mathrm{~cm}^{-1}$ $(5.8-5.9 \mu)$ in the Et- $\mathrm{SO}_{2}-\mathrm{CO}$ spectrum. This band, of course, is quite pronounced in the Et-CO spectrum of run $54 \mathrm{~A}$. 
Thus the evidence of chemical analysis and the infra-red spectrum strongly indicates a terpolymerization. in the $\mathrm{Et}-\mathrm{SO}_{2}-\mathrm{CO}$ system. However, until solvent extractions are conducted on the terpolymer, an unequivocal case cannot be made for the terpolymer. Certainly visual inspection of the terpolymer showed it to be entirely different and the sample was also more cohesive than the powders formed by the other group.

\section{Copolymer Character1zation and Property Measurements}

The first "characterization was made on the thermal stability of the copolymers--both Differential Scanning Calorimetry (DSC) which essentially determines energy associated with a phase transition, such as melting, and thermogravimetric (TGA) and differential thermogravimetric analysis (DTGA) measurements were made up through decomposition temperatures. TGA and DTGA indicates decomposition due to weight loss. The DSC thermograms are given in Figs. 15 through 17 and TGA's and DTGA's are given in Figs. 18 through 20. A summary of the data obtained from the DSC and TGA peaks are given in Table 8. Generally, the thermal stability for all these copolymers are found to be very high. $\left(275^{\circ}\right.$ to $300^{\circ} \mathrm{C}$ ) with the peak decomposition rates stretching up to $420^{\circ} \mathrm{C}$. Melting seems to occur for the Et-CO at $190^{\circ} \mathrm{C}$ and the terpolymer higher, up to $220^{\circ} \mathrm{C}$. Discs have been pressed at elevated temperatures with varying degrees of transparency. Generally the discs were somewhat transparent but hard and brittle.

Measurements of the physical properties of the Et-CO copolymer made by electron beam radiation (bremsstrahlung) from experiment No. 18 have been made and are as: follows: 


\section{Et-CO Copolymer from Run No. 18

\begin{tabular}{|c|}
\hline Composition: \\
\hline
\end{tabular}

$\begin{array}{cl}\text { Melting temp.: } & 192^{\circ} \mathrm{C} \\ \text { Tensile modulus: } & 27,300 \mathrm{psi} \\ \text { Tensile strength: } & 2,000 \mathrm{psi} \\ \text { Elongation: } & 14.2 \%\end{array}$

\section{Conclusions}

A. Et-CO and Et-SO 2 copolymers and terpolymers can be produced with electron beam machine radiation. This is the first time that this has been reported in the literature.

B. The yields and $G$ values for Et-CO copolymers appear to be lower $\left(G=10^{2}\right.$ to $10^{3}$ ) when polymerization is induced by electrons as compared to bremsstrahlung or gamma radiation $\left(G=10^{3}\right.$ to $\left.10^{4}\right)$. The gamma radiation results appear to be intensity dependent indicating a biradical termination step. The high radiation intensity due to electron beam deposition energy could be a factor controlling these lower yields. However, other effects such as system pressure may also have a strong influence.

C. The yields and $G$ values for $\mathrm{Et}^{-\mathrm{SO}_{2}}$ copolymers produced by either electrons or gamma-induced radiation appear to be about the same but much higher $\left(G=10^{4}\right.$ to $10^{5}$ ) than in the Et-CO system. The gamma radiation experiments indicate the yields to be independent of the intensity. A strong unique post-irradiation continued polymerization effect leading to high yields has been observed in the $\mathrm{Et}-\mathrm{SO}_{2}$ systems.

D. The ethylene appears to form a terpolymer with $\mathrm{SO}_{2}$ and $\mathrm{CO}$ based on elemental and IR analytical evidence. The molar content of 
ethylene appears to be as low as $36 \%$ the remainder being $\mathrm{CO}$ and $\mathrm{SO}_{2}$. The polymerization rates are much higher than with ethylene and co alone and are, in general, comparable to the rates with ethylene and $\mathrm{SO}_{2}$

E. According to thermogravimetric analysis, the copolymer of Et-CO is stable to $275^{\circ} \mathrm{C}$, the $\mathrm{Et}-\mathrm{SO}_{2}$ to $300^{\circ} \mathrm{C}$ and the $\mathrm{Et}-\mathrm{CO}-\mathrm{SO}_{2}$ terpolymer to $280^{\circ} \mathrm{C}$.

Further characterization and formulation is needed to determine the value of these copolymers in the market place.

Acknowledgement

The authors acknowledge the cooperation and assistance of Dr. Joseph Silverman, Dr. Marvin Rausch, and Mr. Walter Chappas of the University of Maryland for use of the SREL linear accelerator and for the dosimetry measurements made in the vessel's used in these experiments. The assistance of $\mathrm{Dr}$. Allen Goland and $\mathrm{Mr}$. B. W. Hersey in running the Dynamitron at BNL is much appreciated. The general technical aid of Mr. David Elling is gratefully acknowledged. Also the advice of $\mathrm{Dr}$. Marshall. Cleland of the Radiation Dynamics Corp. on the physics of energy of electrons in matter is much appreciated. 


\section{References.}

1. M. Steinberg, et al., Polyketones and Polysulfones for Conservation in the Polyethylene Polymer Industry, Progress Report No: 1, Oct.Dec. 1977 , BNL-50884.

2. P. Colombo, L. E. Kukacka, J. Fontana, R. N. Chapman, and M. Steinberg, Co-60 Gamma Radiation Induced Copolymerization of Ethylene and Carbon Monoxide, BNL-8554R (October 1964); J. Polymer Sci., Part A-1, $\underline{4}, 29-57$ (1966).

3. P. Colombo, J. Fontana, and M. Steinberg, Radiation-Induced Copolymerization of Ethylene and Sulfur Dioxide in the Liquid and Gas Phase, BNL-11347R; J. Polymer Sci., Part A-1, 6, 3201-3215 (1968).

4. W. L. McLaughlin, A. Miller, S. Fidan, K. Peitersen, and W. B. Pedersen, Radiochromic Plastic Films for Accurate Measurement of Radiation Absorbed Dose and Dose Distributions, Rad. Phys. Chem. 10, 119-127 (1977).

5. M. R. Cleland and J. P. Farrell, Methods for Calculating Energy and Current Requirements for Industrial Electron. Beam Processing, presented at Fourth Conference on Application of Smal1 Accelerators, North Texas State University, Denton, Texas, Oct. 1976; M. R. Cleland, private communication.

6. L. V. Spencer, Energy Dissipation by Fast Electrons, National Bureau of Standards Monograph 1, September 1959.

7. M. J. Berger and S. M. Seltzer, Tables of Energy Losses and Ranges of Electrons and Positrons, National Aeronautics and Space Administration, 1964 .

8. M. Steinberg, Polyketones and Polysulfones for Conservation of Ethylene Polymers, Chem. Engr. Prog. 12 (9), 75-79 (1976). 
Table 1

$\mathrm{Co}^{60}$ GAMMA RADIATION COPOLYMERIZATION OF ETHYLENE AND CO EXPERIMENTAL RESULTS

\begin{tabular}{|c|c|c|c|c|c|c|c|c|c|c|c|c|c|}
\hline $\begin{array}{l}\text { Run } \\
\text { No. . } \\
\end{array}$ & $\% \mathrm{CO}$ & $\begin{array}{l}\text { Vessel } \\
\text { O.D. }\end{array}$ & $\begin{array}{r}\text { size, in. } \\
\text { Wall }\end{array}$ & $\begin{array}{l}\text { Vessel } \\
\text { pretreatment }\end{array}$ & & $\begin{array}{c}\begin{array}{c}\text { Pressure, } \\
\text { atm }\end{array} \\
\end{array}$ & $\begin{array}{c}\text { Intensity, } \\
\text { Mrad/hr }\end{array}$ & $\begin{array}{c}\text { Time, } \\
\text { hr }\end{array}$ & $\begin{array}{l}\text { Dose, } \\
\text { Mrad }\end{array}$ & & $\begin{array}{l}\text { Product } \\
\text { weight, } \\
\mathrm{g}\end{array}$ & $\begin{array}{l}\text { Overall } \\
\text { rate, } Q \text {, } \\
g / \ell-h r\end{array}$ & $\begin{array}{c}\text { Overall } \\
\text { G value, } \\
\text { molecules/ } \\
100 \mathrm{eV} \\
\end{array}$ \\
\hline 22 & 48.8 & $1 / 2$ & 0.035 & Rag wiped & & 146 & 0.60 & 3.00 & 1.80 & & 0.126 & 1.68 & 370 \\
\hline 23 & $"$ & $"$ & $" 1$ & Teflon coated & & 148 & . " " & $"$ & $"$ & & 0.366 & 4.88 & 1080 \\
\hline 24 & " & ." & $"$ : & Acetone flush & hed & 145 & $"$ & $"$ & $"$ & : & 0.092 & 1.22 & 270 \\
\hline 25 & $" 1$ & $1 / 4$ & $"$ " & Teflon coated & & 155 & $" 1$ & $"$. & $"$ & & 0.000 & 0.00 & 0 \\
\hline 44 & $"$ & $1 / 2$ & " & Wire brushed & & 148 & 0.90 & 2.00 & $" 1$ & $\cdot$. & 0.028 & 0.56 & 83 \\
\hline 45 & - " & $"$ & $"$ & Used & & 148 & $" 1$ & $"$ & $"$ & & 0.050 & 1.00 & 147 \\
\hline 46 & $"$ & $"$ & $"$ & $"$ & & 149 & $"$ & $"$ & $"$ & & 0.334 & 6.68 & 984 \\
\hline 47 & $"$ & $"$ & $"$ & $"$. & - & 148 & $"$ & 11 & "1 & . & 0.165 & 3.30 & 486 \\
\hline 48 & $" 1$ & "' & 1 & " & & 148 & $"$ & $"$ & "I & & 0.172 & 3.44 & 507 \\
\hline 49 & $" 1$ & $" 1$ & $\ddots$ & Whre brushed & . & 146 & . 11. & 4.00 & 3.60 & & 0.518 & 5.18 & 763 \\
\hline 50 & $"$ & 2 & 0.500 & $\therefore 11$ & & 144 & 0.60 & 3.00 & 1.80 & & 0.946 & 2.87 & 633 \\
\hline 51 & $"$ & $1 / 2$ & 0.035 & Oxide coated & & 143 & 0.90 & 4.00 & 3.60 & & 0.046 & 0.46 & 68 \\
\hline $52 \mathrm{~A}$ & $"$ & $3 / 4$ & 0.049 & Wirc brushed & & 1.11 & $"$ & 3.00 & 2.70 & & .0 .339 & $1.9 \%$ & 286 \\
\hline $52 \mathrm{~B}$ & $"$ & $1 / 2$ & 0.035 & $" . \quad . "$ & : & 111 & $"$ & “ & $" 1$ & & 0.100 & 1.33 & 196 \\
\hline $53 \mathrm{~A}$ & $"$ & $3 / 4$ & 0.049 & ". . " & 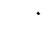 & 146 & $"$ & $"$ & $"$ & & 0.397 & 2.31 & 336 \\
\hline $5 \mathrm{JB}$ & $"$ & $1 / 2$ & 0.035 & $"$ & & 146 & $"$ & $"$ & $"$ & & 0.065 & 0.87 & 127 \\
\hline $54 \mathrm{~A}$ & $"$ & $3 / 4$ & 0.049 & $"$ & & 136 & $"$ & 2.00 & 1.80 & & 0.474 & 4.13 & 600 \\
\hline $54 \mathrm{~B}$ & $"$ & $1 / 2$ & 0.035 & $\cdot "$ & & 136 & $" 1$ & $" 1$ & 11 & & 0.197 & 3.94 & 580 \\
\hline $55 \mathrm{~A}$ & $"$ & $3 / 4$ & 0.049 & Used & & $2140_{(a)}^{(a)}$ & $0.044^{\circ}$ & 18.50 & 0.81 & & 0.957 & 0.90 & 2360 \\
\hline $55 \mathrm{~B}$ & $"$ & $1 / 2$ & 0.035 & $" 1$ & & 2140 & $" 1$ & 11 & 11 & & 0.248 & 0.54 & 1429 \\
\hline $56 \mathrm{~A}$ & $"$ & $3 / 4$ & 0.049 & $"$ & & $2140^{\text {(a) }}$ & $" 1$ & 21.67 & 0.95 & & 0.888 & 0.71 & 1870 \\
\hline $56 \mathrm{~B}$ & $"$ & $1 / 2$ & 0.035 & $"$ & & 2140 (a) & " & " . & $"$ & & 0.547 & 1.01 & 2690 \\
\hline 57 & 49.7 & 2 & 0.500 & " & & $2680(a)$ & 0.030. & 21.00 & 0.63 & & 0.163 & 0.07 & 156 \\
\hline 58 & 49.7 & 2 & 0.500 & $" 1$ & & ن680(a) & $"$ & 69.50 & 2.09 & · & 1.894 & 0.25 & 549 \\
\hline 64 & 49.7 & 2 & 0.500 & " & & $2140^{(\mathrm{a})}$ & 0.030 & 19.00 & 0.57 & & 0.142 & 0.07 & 297 \\
\hline $65 \mathrm{~A}$ & 49.7 & $3 / 4$ & $0: 049$ & $" 1$ & & 139 & 0.90 & 2.00 & 1.80 & & 0.137 & 1.19 & 173 \\
\hline $65 B$ & 49.7 & $1 / 2$ & 0.035 & $" 1$ & & 139 (a) & $"$ & " & $"$ & & 0.068 & 1.36 & 200 \\
\hline 66 & 48.8 & 2 & 0.500 & $" 1$ & & $\sim 140^{(a)}$ & 0.030 & 17.83 & 0.54 & & 0.95 & 0.48 & 2130 \\
\hline $68 \mathrm{~A}$ & 49.9 & $3 / 4$ & 0.049 & 11 & . & 141 & 0.90 & 3.00 & 2.70 & & 0.250 & 1.45 & 211 \\
\hline $68 \mathrm{~B}$ & 49.9 & $1 / 2$ & 0.035 & $"$ & & 141 & • 11 & $"$ & " & & 0.162 & 2.16 & 318 \\
\hline
\end{tabular}

Genera1 notes:

Temperature: $10^{\circ}$ to $13^{\circ} \mathrm{C}$

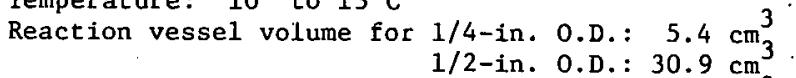

3/4-in. O.D.: $71.1 \mathrm{~cm}^{3}$.

2-in. 0.D.: $110 \mathrm{~cm}^{3}$

Additional volume of gauge, lines, and rupture disc: $220 \mathrm{~cm}^{3}$.

(a) Estimated. Pressure gauge and interconnecting line were removed. 
Table 2

$\mathrm{Co}^{60}$ GAMMA RADIATION COPOLYMERIZATION OF ETHYLENE.AND

$$
\mathrm{SO}_{2} \text { EXPERIMENTAL RESULTS }
$$

\begin{tabular}{|c|c|c|c|c|c|c|c|c|c|c|c|}
\hline $\begin{array}{l}\text {. } \\
\text { Run } \\
\text { No. }\end{array}$ & $\begin{array}{l}\mathrm{SO}_{2} \text {, } \\
\text { weight, }\end{array}$ & $\begin{array}{ll} & \text { Vessel } \\
\text { g } & 0 . \mathrm{D}\end{array}$ & $\begin{array}{l}\text { size, in. } \\
\text { Wall }\end{array}$ & $\begin{array}{c}\text { Vessel } \\
\text { pretreatment }\end{array}$ & $\begin{array}{c}\text { Pressure, } \\
\text { atm }\end{array}$ & $\begin{array}{c}\text { Intensity, } \\
\text { Mrad/hr }\end{array}$ & $\begin{array}{c}\text { Time, } \\
\text { hr }\end{array}$ & $\begin{array}{l}\text { Dose, } \\
\text { Mrad }\end{array}$ & $\begin{array}{c}\text { Product } \\
\text { weight, } \\
\mathrm{g}\end{array}$ & $\begin{array}{l}\text { Overall } \\
\text { rate, Q, } \\
\text { g/l-hr }\end{array}$ & $\begin{array}{l}\text { Overall } \\
\text { G value, } \\
\text { molecules/ } \\
100 \mathrm{eV}\end{array}$ \\
\hline 26 & 11.2 & $1 / 2$ & 0.035 & Teflon coated & $98-75$ & 0.60 & 3.00 & 1.80 & 0.358 & 28.6 & $1.36 \times 10^{3}$ \\
\hline 69 & 25.5 & 2 & 0.500 & Used & $571-204^{(a)}$ & $"$. & 0.250 & $1.15^{\circ}$ & 25.0 & 909 & $6.9 \times 10^{4}$ \\
\hline 70 & $"$ & 2 & 0.500 & $"$ & $51 \%-245^{(a)}$ & $"$ & 0.183 & 0.11 & 18.2 & 903 & $6.8 \times 10^{4}$ \\
\hline 71 & $"$ & 2 & 0.500 & " & $540-225^{(a, b)}$ & 0.30 & 3.67 & 0.11 & 24.9 & 61.7 & $9.3 \times 10^{4}$ \\
\hline
\end{tabular}

Genera1 notes:

Temperature: $10^{\circ}$ to $13^{\circ} \mathrm{C}$.
Redillun vessel volume for $1 / 2-$ in. 0.D.: $30,9 \mathrm{~cm}^{3}$

2-in. 0.D.: $110 \mathrm{~cm}^{3}$

Additional volume of gauge, lines, and rupture disc: $\sim 20 \mathrm{~cm}^{3}$.

(a) Final pressure obtained after post-irradiation effect.

(b) Estimated. Pressure gauge and interconnecting line was removed.

(c) Overall $G$ value includes post-irradiation effect.

Table 3

\section{ELECTRON ENERGY UTILIZATION EFFICIENCIES FOR REACTION VESSELS}

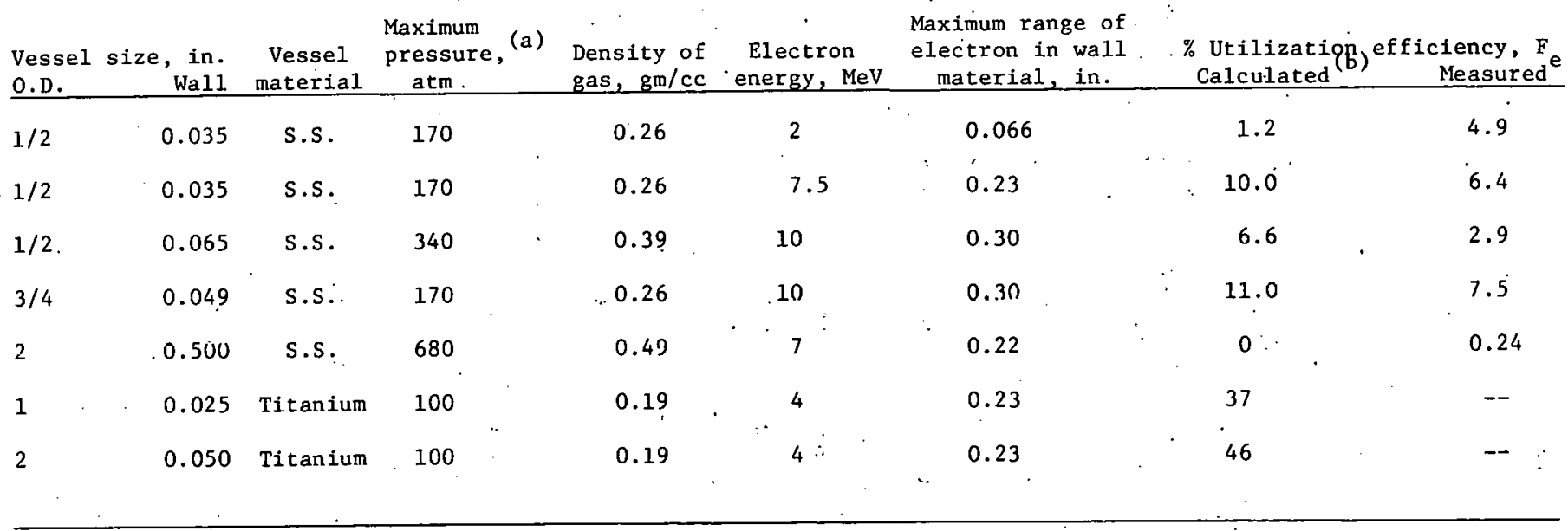

(a) Based on allowable stress $S=15,000$ psi for stainless steel and $S=30,000$ psi for titanium.

(b) An estimated additional efficiency loss of $62 \%$ is iricluded due to curvature of tube for $1 / 2-$ and $3 / 4-1$. $0 . \mathrm{D}$. tubes. Calculated value does not include bremsstrahlung. 
Table 4

ELECTRON BEAM COPOLYMERIZATION OF ETHYLENE AND CO EXPERIMENTAL RESULTS

\begin{tabular}{|c|c|c|c|c|c|c|c|c|c|c|c|c|c|}
\hline & $\begin{array}{l}\text { Run } \\
\text { No. } \\
\end{array}$ & $\begin{array}{l}\text { Vesse1 } \\
\text { O.D. }\end{array}$ & $\begin{array}{r}\text { size, in. } \\
\text { Wall } \\
\end{array}$ & $\begin{array}{c}\text { Pressure, } \\
\text { atm }\end{array}$ & $\begin{array}{c}\text { Electr } \supset \eta(a) \\
\text { energy, } \\
\mathrm{MeV}\end{array}$ & $\begin{array}{c}\text { Current, } \\
\mu \mathrm{A}\end{array}$ & $\begin{array}{c}\text { Time, } \\
\mathrm{hr}\end{array}$ & $\begin{array}{r}\text { Intensity, } \\
\mathrm{Mrad} / \mathrm{hr}\end{array}$ & $\begin{array}{l}\text { Dose, } \\
\text { Mrad }\end{array}$ & $\begin{array}{l}\text { \% Electran energy } \\
\text { deposited directly } \\
\text { in reactent gas }\end{array}$ & $\begin{array}{l}\text { Froduct } \\
\text { weight, } \\
\mathrm{g} \\
\end{array}$ & $\begin{array}{l}\text { Overall } \\
\text { rate, } Q, \\
g / \ell-\mathrm{hr}\end{array}$ & $\begin{array}{l}\text { Overall } \\
\text { G value, } \\
\text { molecules/ } \\
100 \mathrm{eV} \\
\end{array}$ \\
\hline$\cdot$ & 18 & 2 & 0.500 & $483-350$ & 7 & 10 & 0.50 & 1.2 & 0.6 & 0 & 6.0 & 109 & 7000 \\
\hline & 27 & $1 / 2$ & 0.035 & 169 & 7.5 & 0.7 & 0.20 & 15.0 & 3.0 & 6.4 & 0.027 & 4.36 & 39 \\
\hline & 28 & $1 / 2$ & 0.035 & 156 & 7.5 & 1.0 & 0.40 & 21.3 & 8.5 & 6.4 & 0.066 & 5.33 & 33 \\
\hline & 30 & $1 / 2$ & 0.035 & 143 & 7.5 & 0.9 & 0.40 & 18.8 & 7.5 & 6.4 & 0.078 & 6.30 & 45 \\
\hline & 31 & $1 / 2$ & 0.035 & 170 & 7.5 & 1.0 & 0.40 & 21.3 & 8.5 & 6.4 & 0.087 & 7.03 & 44 \\
\hline 1 & 38 & $1 / 2$ & 0.035 & 163 & 2 & 2.7 & 1.00 & 11.7 & 11.7 & 4.9 & 0.275 & 8.89 & 101 \\
\hline$\stackrel{N}{\leftarrow}$ & 39 & $1 / 2$ & 0.035 & 116 & 2 & 2.9 & 0.50 & 12.4 & 6.2 & 4.9 & 0.067 & .4 .33 & 46 \\
\hline 1 & 40 & $1 / 2$ & 0.035 & 153 & 2 & 7.2 & 0.42 & 31.2 & 13.1 & 4.9. & 0.072 & 5.54 & 23 \\
\hline . & 41 & $1 / 2$ & 0.035 & 156 & 2 & 9.7 & 0.30 & 42.7 & 12.8 & 4.9 & 0.078 & 8.40 & 26 \\
\hline & 59 & $3 / 4$ & 0.049 & 153 & 10 & 0.2 & 0.50 & 2.8 & 1.4 & 7.5 & 0.128 & 3.60 & 165 \\
\hline & 60 & $1 / 2$ & 0.065 & 224 & 10 & 0.2 & 0.50 & 2.6 & 1.3 & 2.9 & 0.007 & 0.64 & 25 \\
\hline & 61 & $3 / 4$ & 0.049 & 136 & 10 & 0.4 & 0.50 & 5.7 & 2.9 & 7.5 & 0.180 & $5.06^{\circ}$ & 116 \\
\hline & 62 & $1 / 2$ & 0.035 & 170 & 5 & 0.4 & 0.50 & 5.7 & 2.9 & $\sim j .0$ & 0.041 & 2.65 & 55 \\
\hline
\end{tabular}

(a) 2 . MeV runs conducted with the Dynamitron at BNL.

5-10 MeV runs conducted with the SREL E-Linac at U. of Maryiand.

(b) See Table 3 . 
Table 5

ELECTRON BEAM COPOLYMERIZATION OF ETHYLENE AND SO ${ }_{2}$ EXPERIMENTAL RESULTS

\begin{tabular}{|c|c|c|c|c|c|c|c|c|c|c|c|c|c|c|}
\hline & & $\begin{array}{l}\text { Run } \\
\text { No. }\end{array}$ & $\begin{array}{l}\text { Jessel } \\
\text { O.D. }\end{array}$ & $\begin{array}{r}\text { size, in. } \\
\text { Wall }\end{array}$ & $\begin{array}{c}\text { Pressure, } \\
\text { atm }\end{array}$ & $\begin{array}{c}\begin{array}{c}\text { Electron } \\
\text { energy } \\
\text { MeV }\end{array} \\
\end{array}$ & $\begin{array}{c}\text { Current } \\
\mu \mathrm{A}\end{array}$ & $\begin{array}{c}\text { Time, } \\
\mathrm{hr}\end{array}$ & $\begin{array}{c}\text { Intensity, } \\
\mathrm{Mrad} / \mathrm{hr}\end{array}$ & $\begin{array}{l}\text { Dose, } \\
\text { Mrad }\end{array}$ & $\begin{array}{l}\text { \% Electron energy } \\
\text { deposited directly } \\
\text { on reactant gas }\end{array}$ & $\begin{array}{c}\text { Product } \\
\text { weight, } \\
\mathrm{g}\end{array}$ & $\begin{array}{l}\text { Overall } \\
\text { rate, } Q, \\
\text { g/l-hr }\end{array}$ & $\begin{array}{c}\text { Overall (b) } \\
\text { G value, } \\
\text { molecules/ } \\
100 \mathrm{eV}\end{array}$ \\
\hline & . & 29 & $1 / 2$ & .0 .035 & $90-70$ & 7.5 & 0.6 & 0.50 & 12.6 & 6.3 & $6: 4$ & 7.39 & 477 & 1300 \\
\hline & $=$ & 34 & $1 / 2$ & 0.035 & $61-56$ & $\cdot 2$ & 1.0 & 0.50 & 4.4 & 2.2 & 6.4 & 7.72 & $499+$ & 3990 \\
\hline 1 & . & 35 & $1 / 2$ & 0.035 & $85-70$ & 2 & .2 .0 & 0.50 & 8.8 & 4.4 & 6.4 & 8.79 & 568 & 2270 \\
\hline & . & & & $*$ & & & & & & & 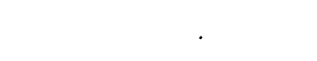 & & & \\
\hline
\end{tabular}

General notes:

$11.2 \mathrm{~g} \mathrm{SO}_{2}$ - balance approx. $16.3 \mathrm{~g}$ ethylene (1iquid and gaseous $\mathrm{SO}_{2}$ present in vessel). Reaction vessel volume: $30.9 \mathrm{~cm}$.

Additional volume of gauge, lines, and rupture disc: $\sim 20 \mathrm{~cm}^{3}$.

(a) $2 \mathrm{MeV}$ runs conducted with the Dynamitron (BNL);

$7.5 \mathrm{MeV}$ runs conducted with the SREL E-Linac (U. of Maryland).

- (b) Molecular weight of average polymer unit assumed to be 43.2 . 
Table 6

TERPOLYMERIZATION OF ETHYLENE WITH $\mathrm{SO}_{2}$ AND CO EXPERIMENIAL RESULTS

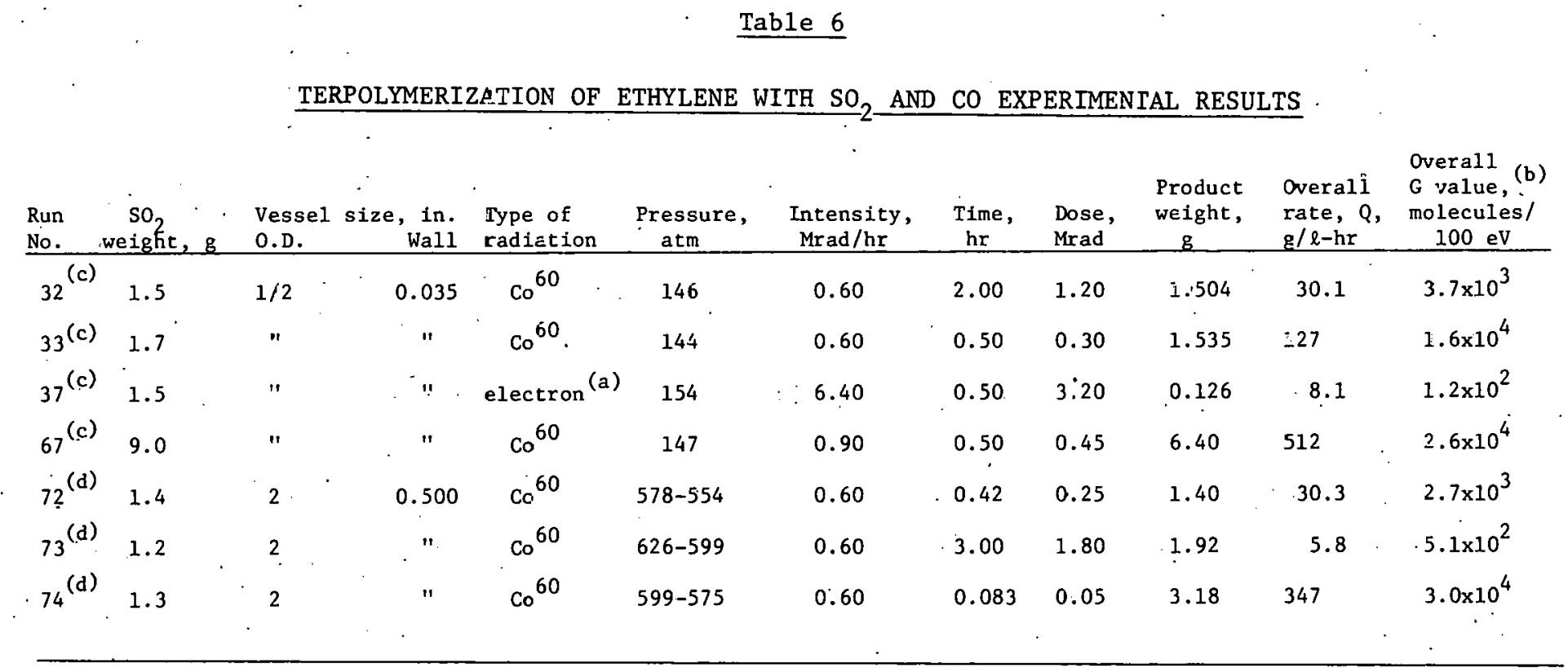

\section{General notes:}

Temperature: $10^{\circ}$ to $13^{\circ} \mathrm{C}$.

Reaction vessel volume for $1 / 2$-ir. 0. . : $30.9 \mathrm{~cm}^{3}$
$2-1$ C. 0. D.: $110 \mathrm{~cm}^{3}$

Additional volume of gauge, lines, and rupture disc: $\sim 20 \mathrm{~cm}^{3}$.

(a) $2 \mathrm{MeV}$ electron beam at Dynami-ron, BNL.

(b) Molecular weight of average polymer unit assumed to be 43.2.

(c) Liquid and gaseous $\mathrm{SO}_{2}$ phase sresent in vessel.

(d) Only gas phase present. 
Table 7

$\underline{\text { ETHYLENE-SO }}_{2}-$ CO TERPOLYMER ANALYSES

\begin{tabular}{|c|c|c|c|c|c|c|c|}
\hline Run No. & wt\% C & wt\% H & wt $\% \mathrm{~S}$ & wt\% $0^{(a)}$ & $\mathrm{M} \% \mathrm{C}_{2} \mathrm{H}_{4}$ & $\mathrm{M} \% \mathrm{SO}_{2}$ & M\% CO \\
\hline $32^{(b)}$ & 27.49 & 4.74 & 33.05 & 34.23 & 49.9 & 46.5 & 3.6 \\
\hline $33^{(b)}$ & 25.85 & 4.51 & 33.95 & 34.26 & 49.7 & 49.4 & 0.9 \\
\hline 37 & 41.1 & 5.68 & 23.65 & 29.57 & 58.0 & 28.0 & 14.0 \\
\hline $67 \mathrm{G}^{(\mathrm{c})}$ & 25.2 & 4.17 & 32.3 & 38.3 & 38.7 & 44.9 & 16.4 \\
\hline $67 \mathrm{~L}^{(\mathrm{d})}$ & 26.0 & 4.56 & 30.58 & 38.9 & 36.1 & 41.7 & 22.2 \\
\hline
\end{tabular}

(a) Oxygen determined by difference.

(b) Data furnished by TCI.

(c) Gas phase sample from run 67 .

(d) Liquid phase sample from run 67 .

Table 8

THERMAL CHARACTERISTICS OF THE COPOLYMERS DERIVED FROM DSC, TGA, AND DTGA ANALYSES

Run

No. Copolymer

67

$\begin{array}{llllr}18 & 50-50 & 190 & 275 & 420 \\ 29 & \text { Et }-\mathrm{SO}_{2} & 50-50 & 155 & 300 \\ 67 & \mathrm{Et}-\mathrm{SO}_{2}-\mathrm{CO} & 36-42-22 & 220 & 280\end{array}$

DSC

peak melting or

transition, ${ }^{\circ} \mathrm{C}$

190

155

220
TGA

onset of decomposition, ${ }^{\circ} \mathrm{C}$

275

300

280
DTGA peak decomposition, ${ }^{\circ} \mathrm{C}$ 


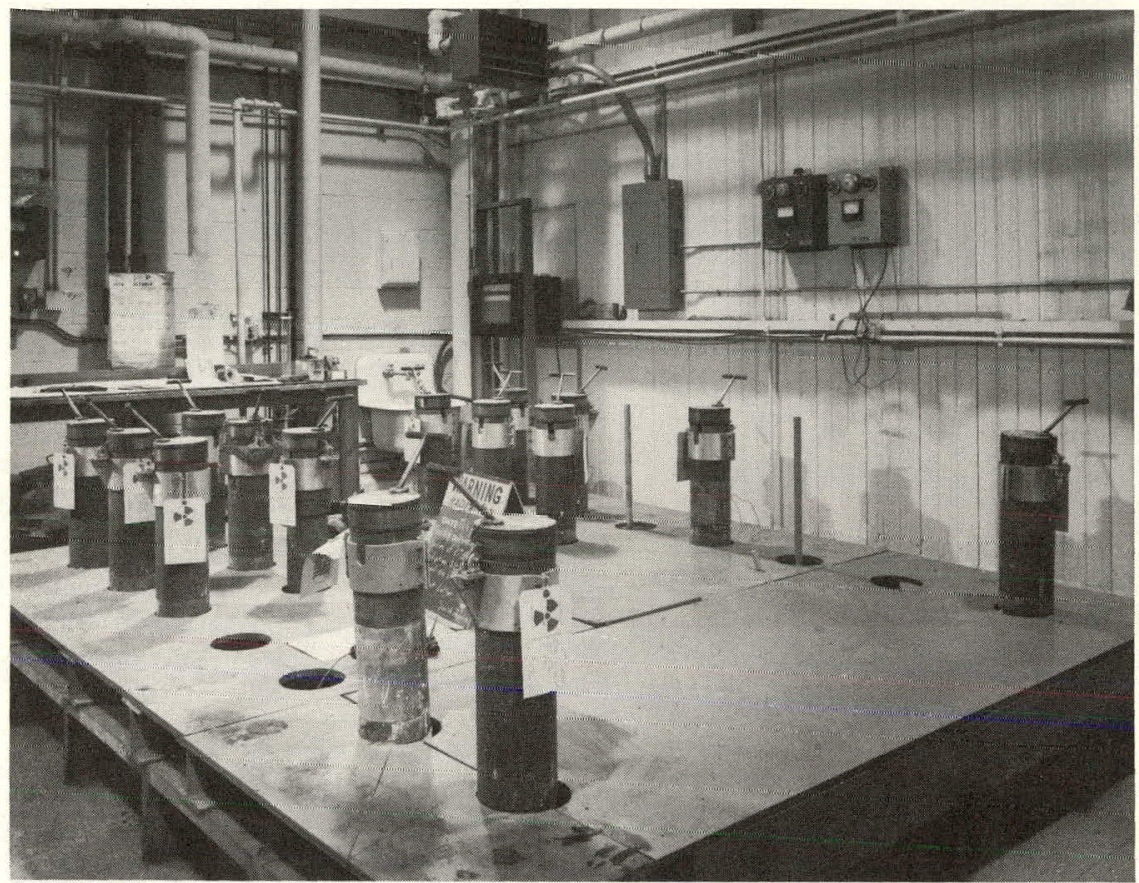

Figure 1. BNL Co ${ }^{\overline{60}}$ gamma irradiation facility.

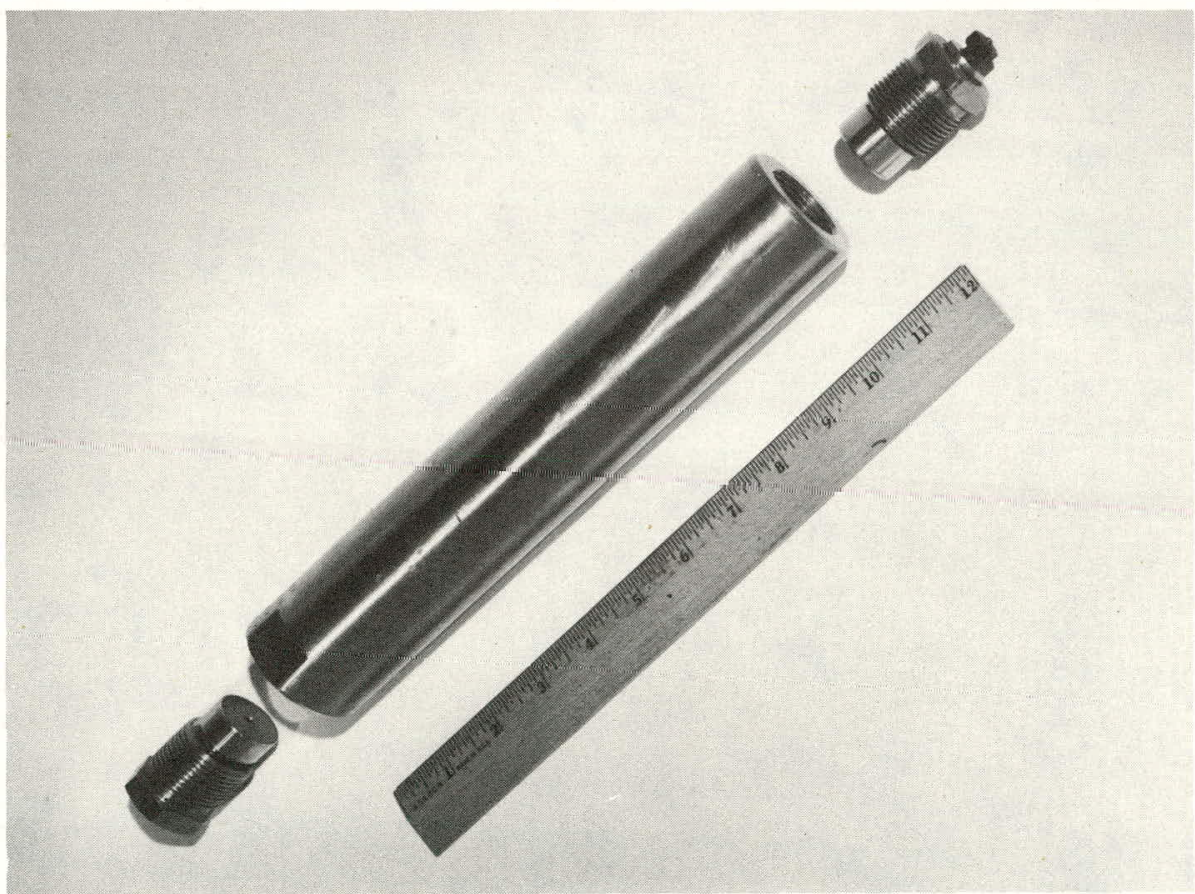

Figure 2. Heavy walled 2-in. O.D. reaction vesse1. 


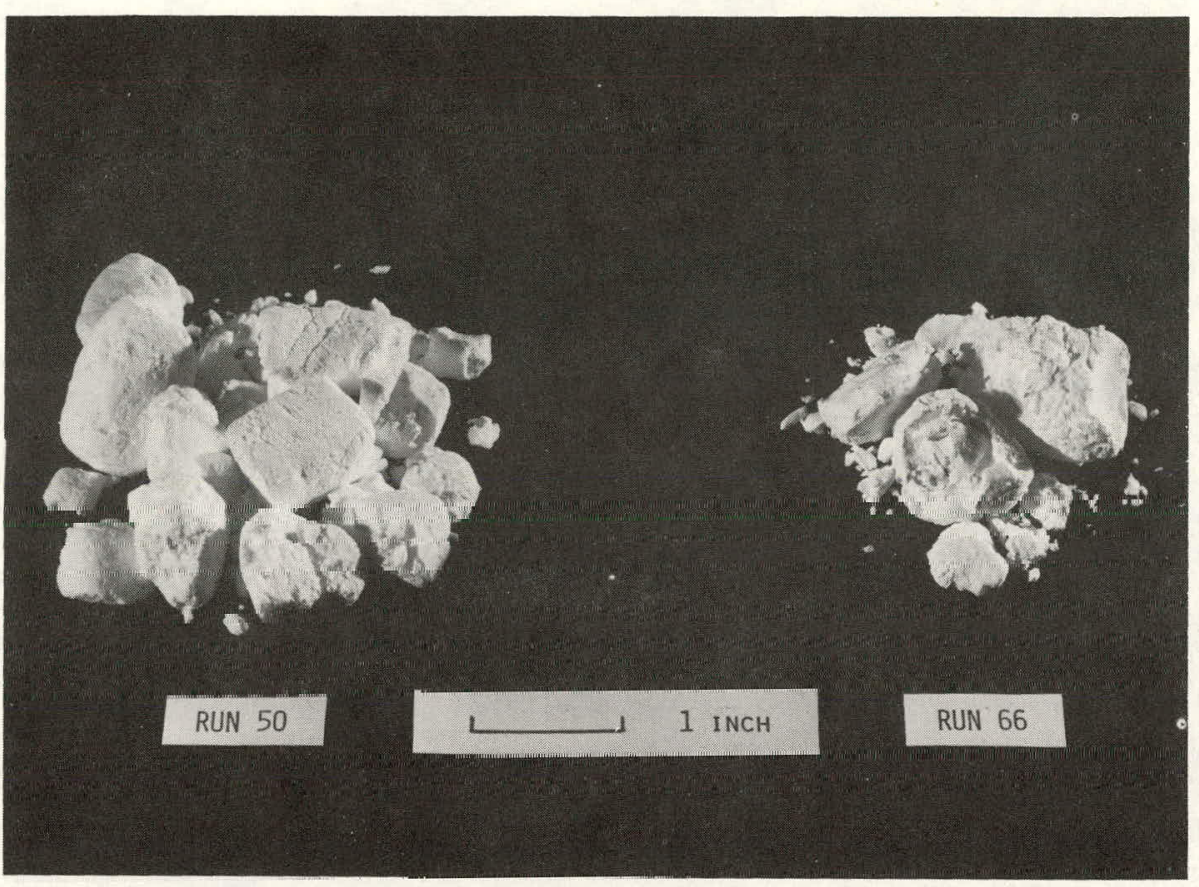

Figure 3. Et-CO copolymer from runs 50 and 66 .

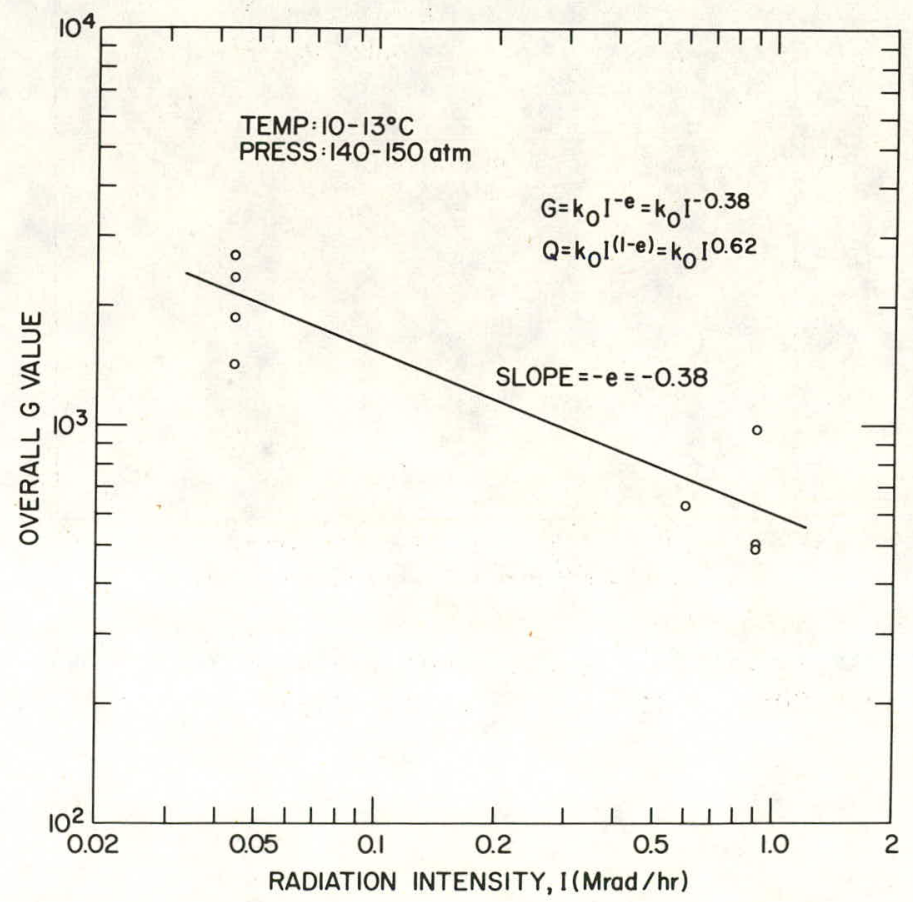

Figure 4. Co ${ }^{60}$ gamma copolymerization of ethylene and $\mathrm{CO}$. Overall $\mathrm{G}$ value vs. radiation intensity. 


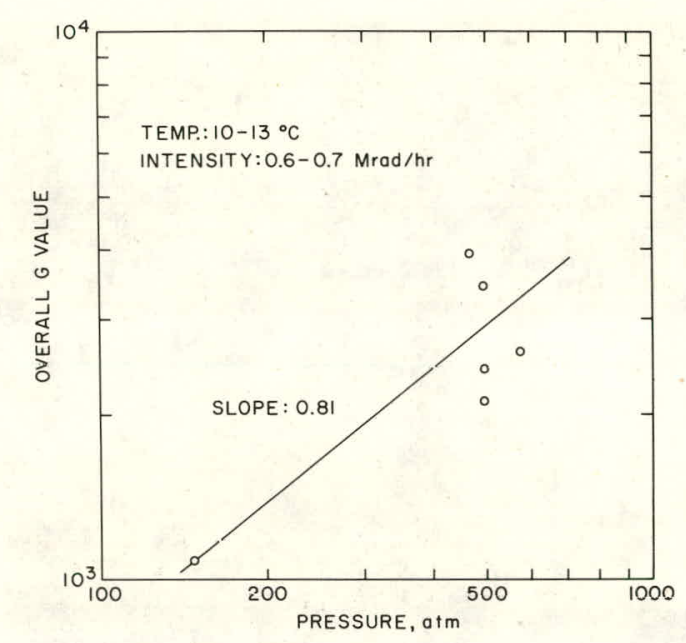

Figure 5. Co ${ }^{60}$ gamma copolymerization of ethylene and $\mathrm{CO}$. Overall $\mathrm{G}$ value ve. pressure.

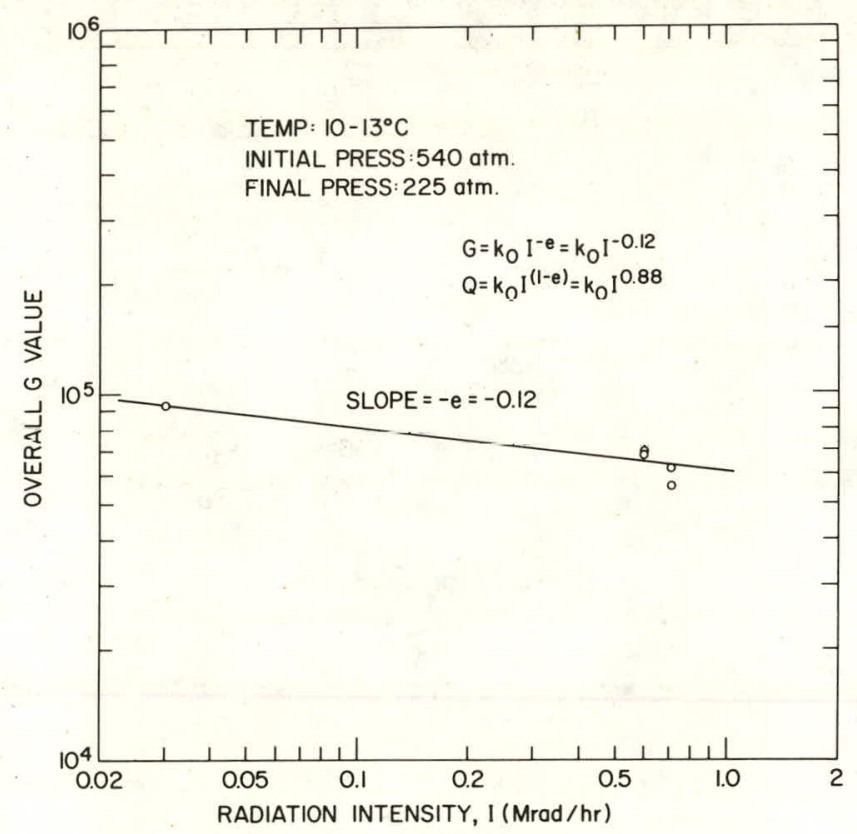

Figure 6. Co ${ }^{60}$ gamma copolymerization of ethylene and $\mathrm{SO}_{2}$. Overall $\mathrm{G}$ value vs. radiation intensity. 


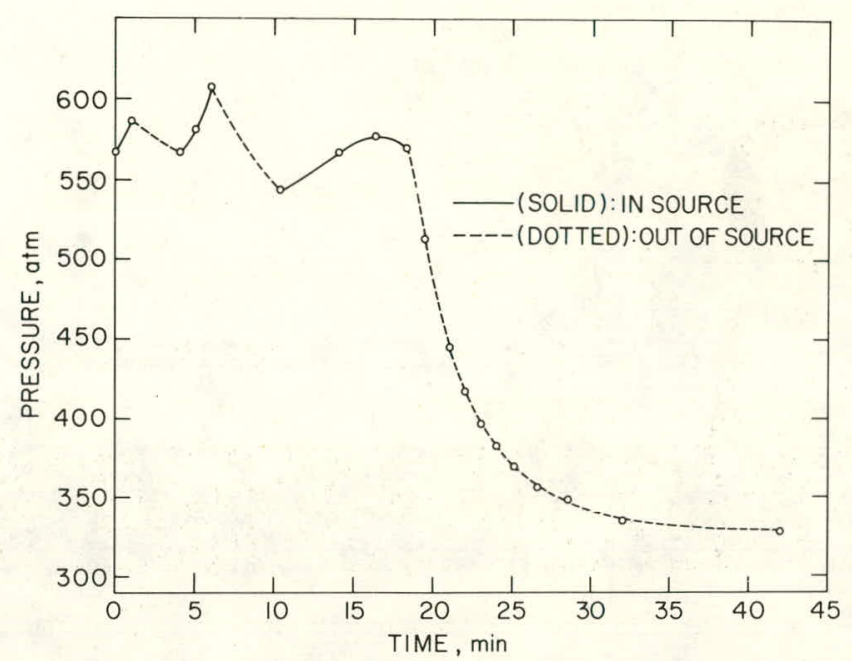

Figure 7. Co ${ }^{60}$ gamma copolymerization of ethylene and $\mathrm{SO}_{2}$. Pressure vs. time - run 70 .

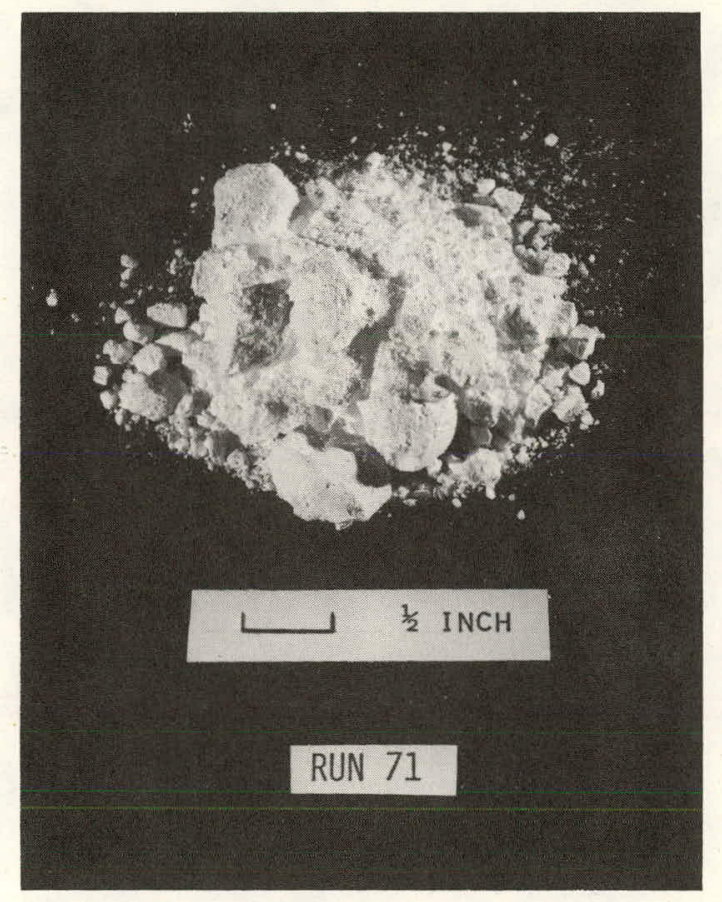

Figure 8. Et-SO 2 copolymer from run 71 . 


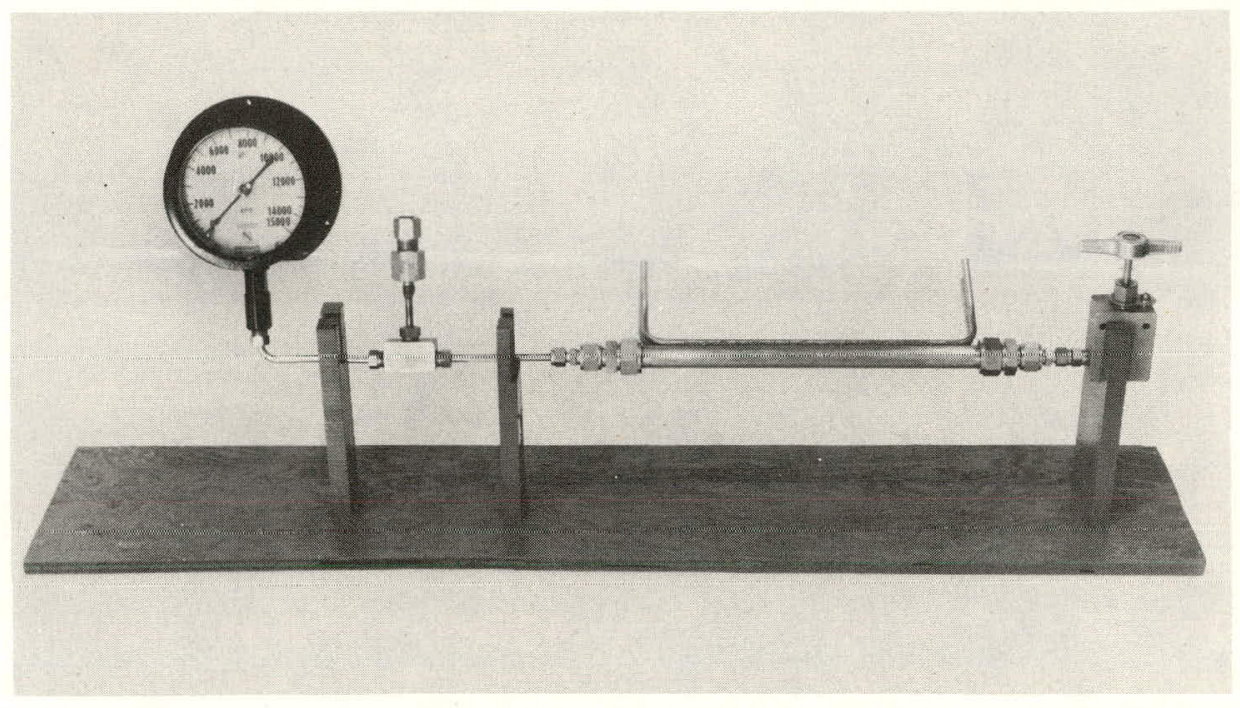

Figure 9. Assembled 3/4-in. O.D. reaction vesse1 with pressure gauge, rupture disc, and valve.

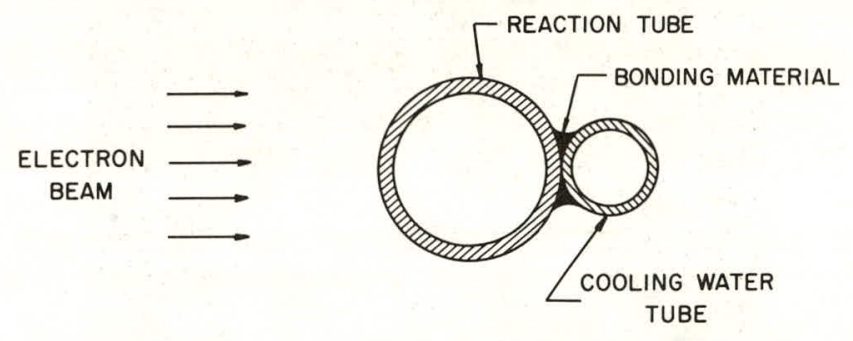

Figure 10. Schematic of typical reaction vesse1 for electron beam copolymerization studies. 


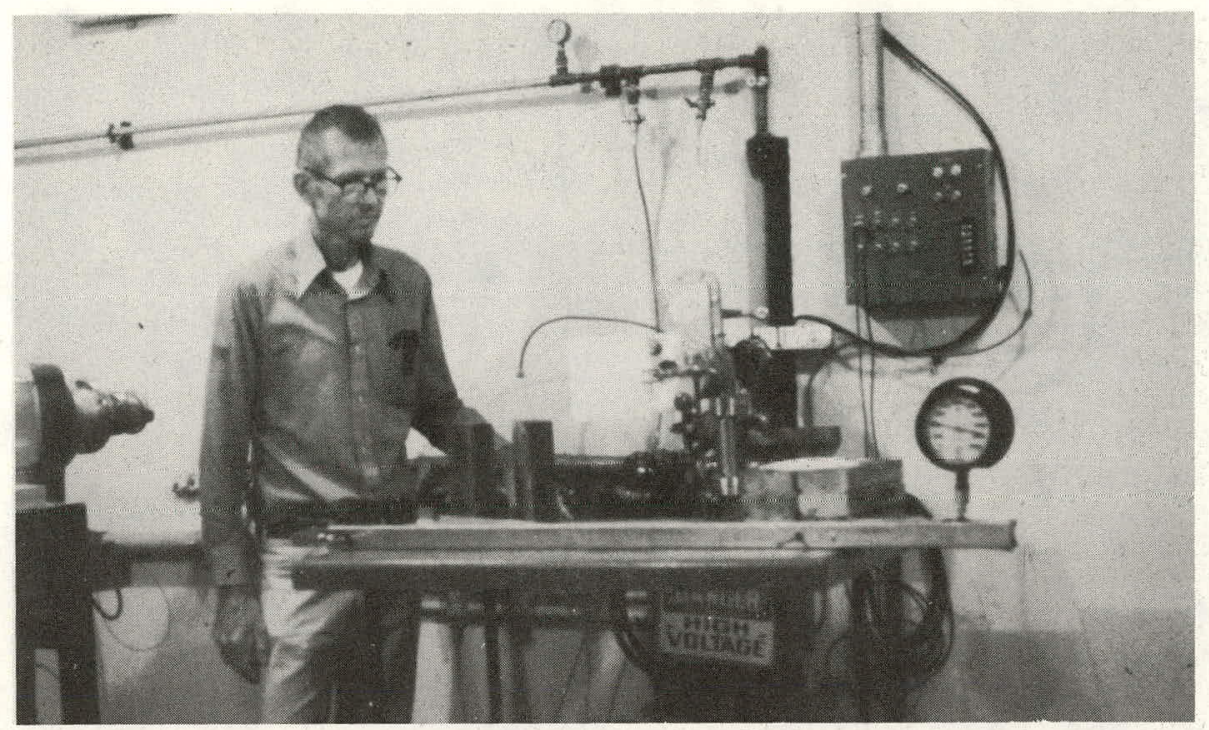

Figure 11. Reaction vessel in position for electron beam irradiation at E-Linac.

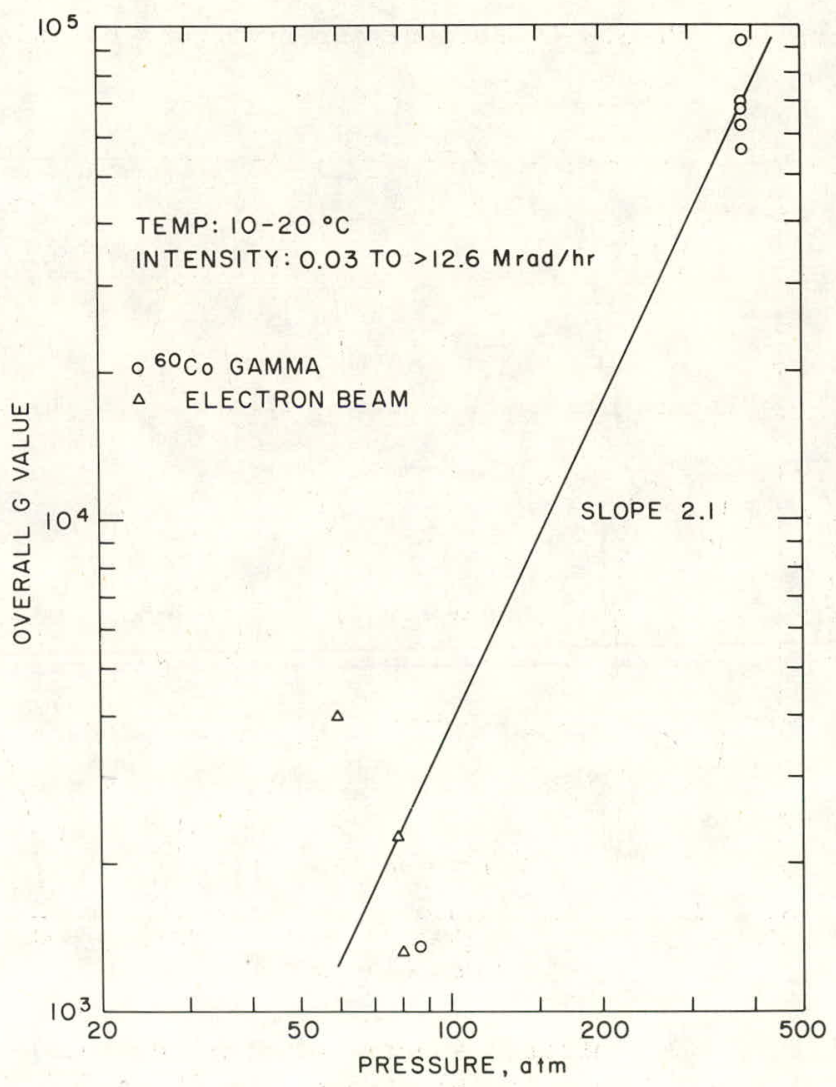

Figure 12. Co ${ }^{60}$ gamma and electron beam copolymerization of ethylene and $\mathrm{SO}_{2}$. Overall $\mathrm{G}$ value vs. pressure. 


\section{$\longrightarrow \frac{1}{2}$ INCH}

\section{$\triangle$}

Figure 13. Et- $\mathrm{SO}_{2}-\mathrm{CO}$ termpolymer from runs 67 and 73.

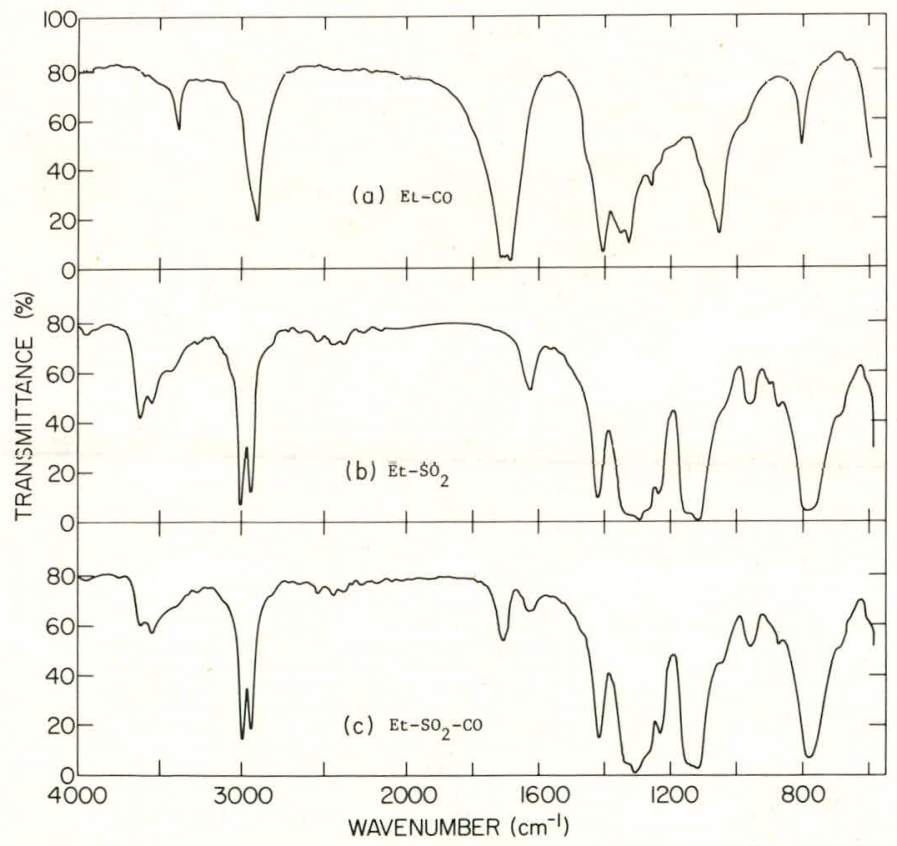

Figure 14. Infrared spectra of ethylene copolymers; (a) $\mathrm{Et}-\mathrm{CO}$, run $54 \mathrm{~A}$; (b) $\mathrm{Et}-\mathrm{SO}_{2}$, run 70 ; and (c) Et$\mathrm{SO}_{2}-\mathrm{CO}$, run 72 . 


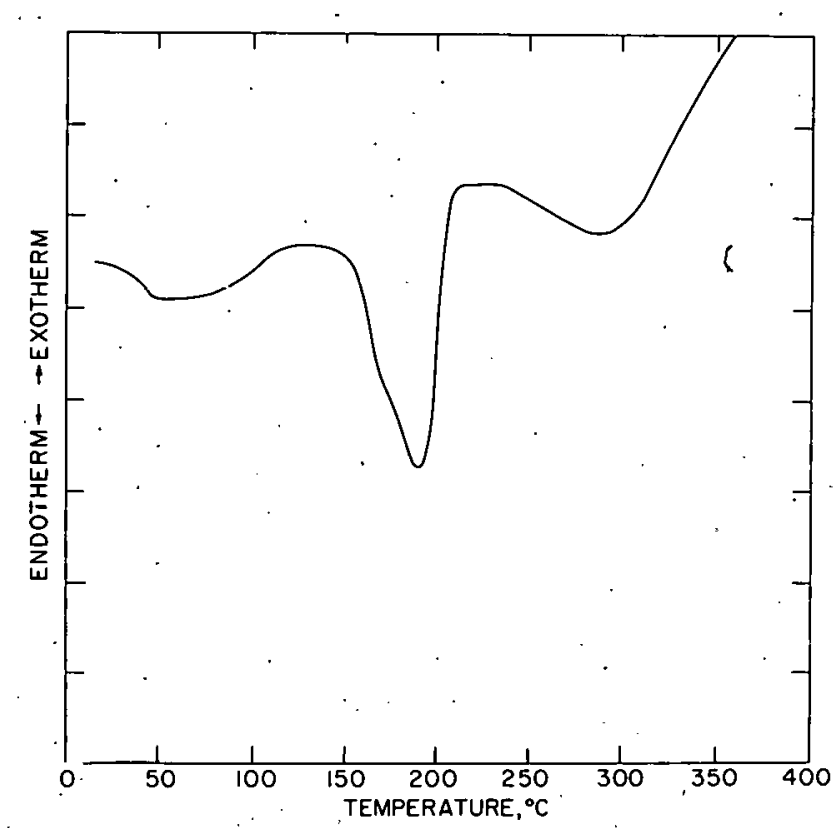

Figure 15. Electron beam copolymerization of ethylene and $\mathrm{CO}$. Differential scanning calorimeter - run 18 .

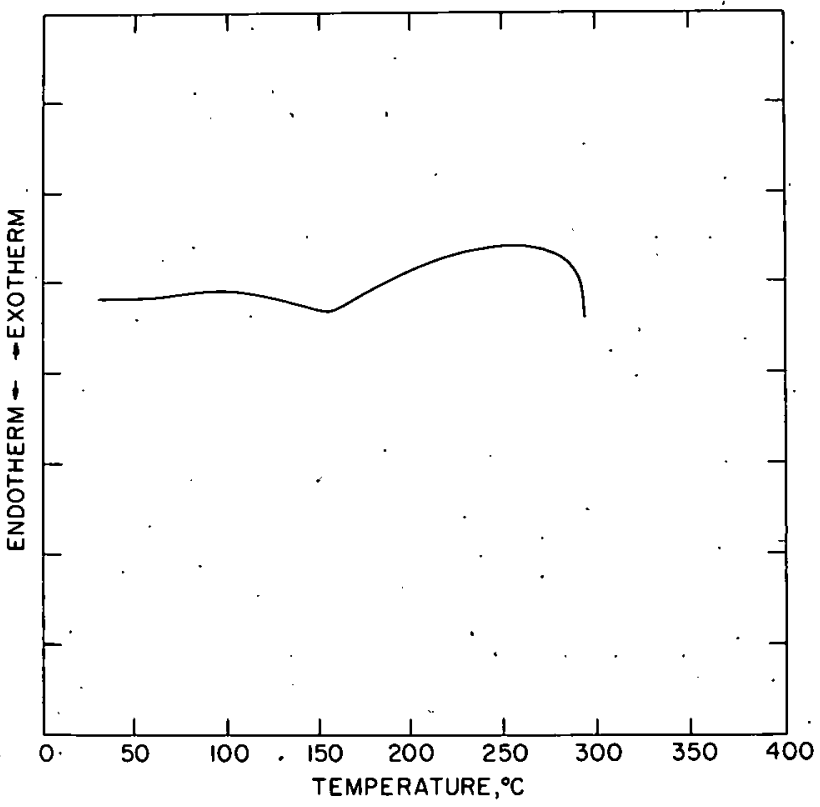

Figure 16. Electron beam copolymerization of ethylene and $\mathrm{SO}_{2}$. Differential scanning calorimeter - run 29 . 


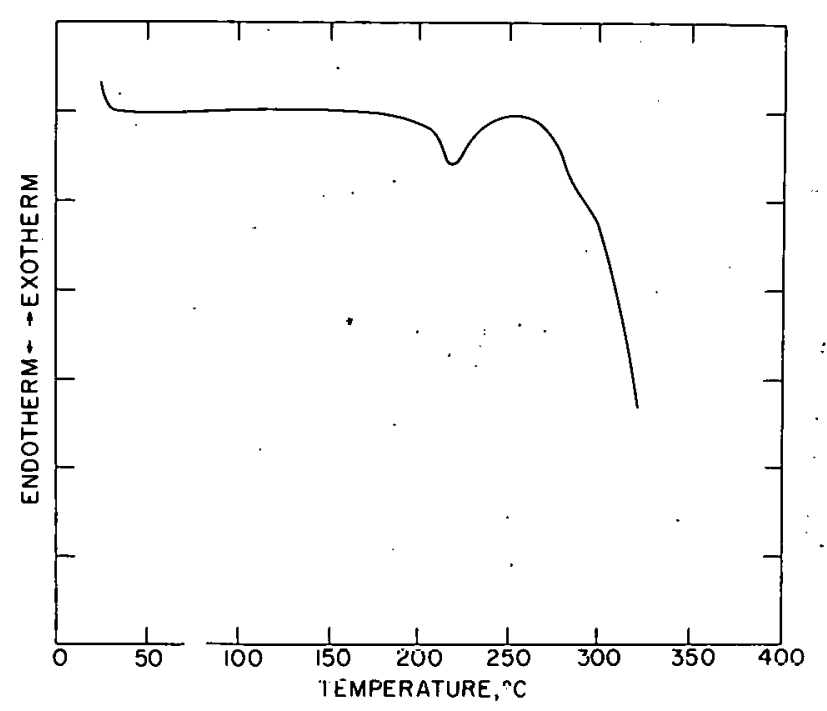

Figure 17. Co ${ }^{60}$ gamma terpolymerization of ethylene, $\mathrm{SO}_{2}$, and $\mathrm{Co}$. Diffcrential scanning calorimeter - run 67 .

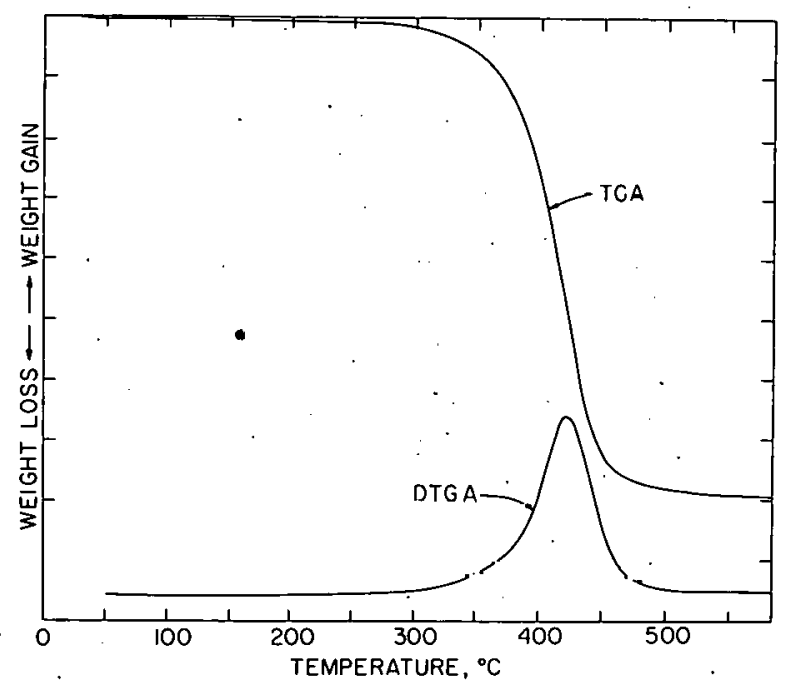

Figure 18. Flectron beam copolymerization of ethylene and Co. Thermogravimetric analysis - run 18. 


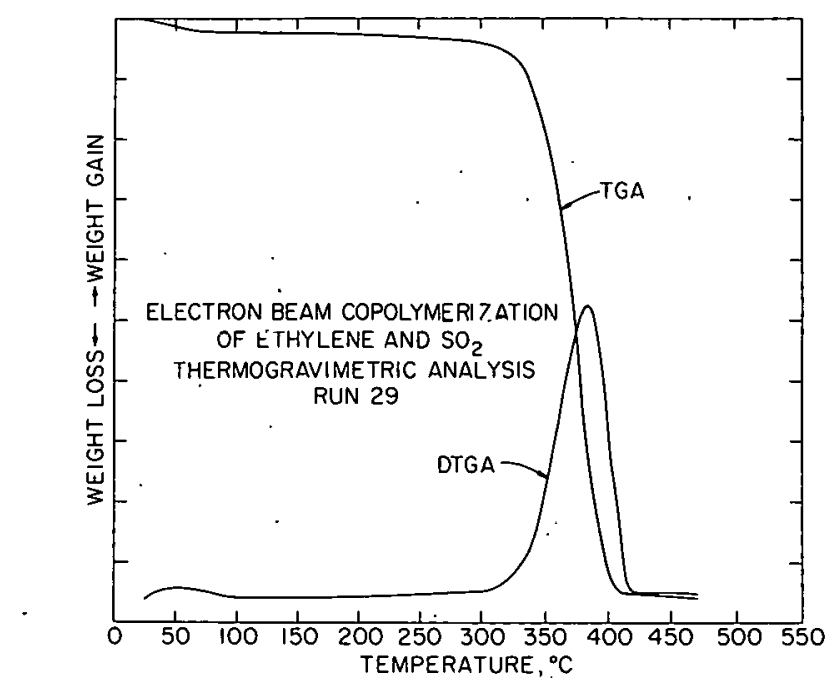

Figure 19. Electron beam copolymerization of ethylene and $\mathrm{SO}_{2}$. Thermogravimetric analysis - run $2 y$.

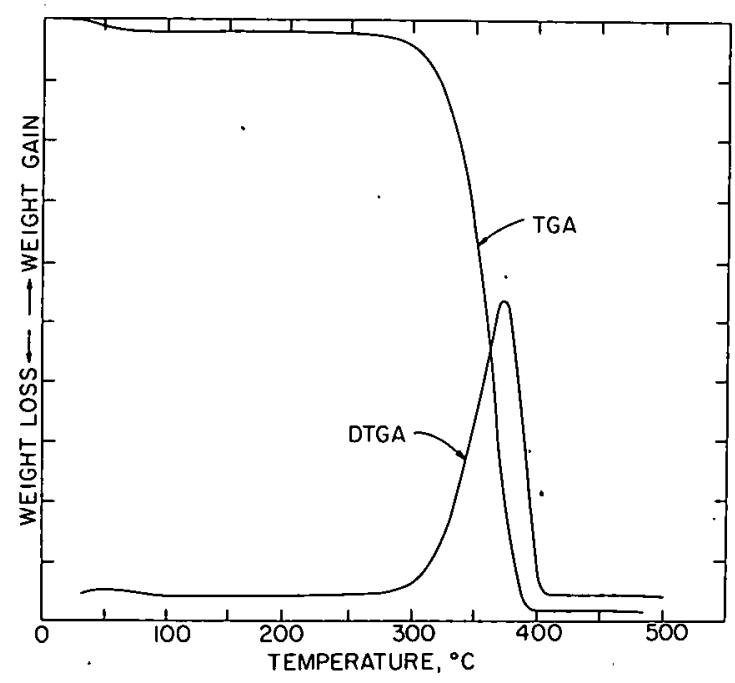

Figure 20. $\mathrm{Co}^{60}$ gamma terpolymerization of ethylene,

$\mathrm{SO}_{2}$, and $\mathrm{CO}$. Thermogravimetric analysis - run 67 . 
